\title{
Number size distributions and seasonality of submicron particles in Europe 2008-2009
}

\author{
A. Asmi ${ }^{1}$, A. Wiedensohler ${ }^{2}$, P. Laj ${ }^{3}$, A.-M. Fjaeraa ${ }^{4}$, K. Sellegri ${ }^{5}$, W. Birmili ${ }^{2}$, E. Weingartner ${ }^{6}$, U. Baltensperger ${ }^{6}$, \\ V. Zdimal ${ }^{7}$, N. Zikova ${ }^{7}$, J.-P. Putaud ${ }^{8}$, A. Marinoni $^{9}$, P. Tunved ${ }^{10}$, H.-C. Hansson ${ }^{10}$, M. Fiebig ${ }^{4}$, N. Kivekäs ${ }^{11}$, \\ H. Lihavainen ${ }^{11}$, E. Asmi ${ }^{11}$, V. Ulevicius ${ }^{12}$, P. P. Aalto ${ }^{1}$, E. Swietlicki ${ }^{13}$, A. Kristensson ${ }^{13}$, N. Mihalopoulos ${ }^{14}$, \\ N. Kalivitis ${ }^{14}$, I. Kalapov ${ }^{15}$, G. Kiss ${ }^{16}$, G. de Leeuw ${ }^{11,17}$, B. Henzing ${ }^{17}$, R. M. Harrison ${ }^{18}$, D. Beddows ${ }^{18}$, C. O'Dowd ${ }^{19}$, \\ S. G. Jennings ${ }^{19}$, H. Flentje ${ }^{20}$, K. Weinhold ${ }^{2}$, F. Meinhardt ${ }^{21}$, L. Ries ${ }^{21}$, and M. Kulmala ${ }^{1}$ \\ ${ }^{1}$ Department of Physics, University of Helsinki, P.O. Box 64, Helsinki, Finland \\ ${ }^{2}$ Leibniz Institute for Tropospheric Research, Permoserstraße 15, 04318 Leipzig, Germany \\ ${ }^{3}$ Laboratoire de Glaciologie et Géophysique de l'Environnement Université Joseph Fourier, Grenoble 1/CNRS, 38400 St. \\ Martin d'Hères, France \\ ${ }^{4}$ Norwegian Institute for Air Research Instituttveien 18, 2027 Kjeller, Norway \\ ${ }^{5}$ Laboratoire de Météorologie Physique, UMR 6016, CNRS/University of Clermont-Ferrand, Clermont-Ferrand, France \\ ${ }^{6}$ Laboratory of Atmospheric Chemistry, Paul Scherrer Institut, 5232 Villigen PSI, Switzerland \\ ${ }^{7}$ Laboratory of Aerosol Chemistry and Physics, Institute of Chemical Process Fundamentals of the AS CR, v.v.i., Rozvojova \\ 135, 16502 Praha 6, Czech Republic \\ ${ }^{8}$ European commission, Joint Research Centre, Institute for Environment and Sustainability, 21027 Ispra (VA), Italy \\ ${ }^{9}$ CNR-ISAC, Institute of Atmospheric Sciences and Climate, 40129, Bologna, Italy \\ ${ }^{10}$ Department of Applied Environmental Science (ITM), Stockholm University, Svante Arrhenius väg 8, \\ 10691 Stockholm, Sweden \\ ${ }^{11}$ Research and Development, Finnish Meteorological Institute, Helsinki, Finland \\ ${ }^{12}$ Center for Physical Sciences and Technology Savanoriu 231, 02300 Vilnius, Lithuania \\ ${ }^{13}$ Department of Physics, Lund University, P.O. Box 118, 22100 Lund, Sweden \\ ${ }^{14}$ Environmental Chemical Processes Laboratory, Department of Chemistry, University of Crete, Greece \\ ${ }^{15}$ Institute of Nuclear Research and Nuclear Energy, Bulgarian Academy of Sciences, Blvd. Tzarigradsko chaussee, 72, \\ 1784 Sofia, Bulgaria \\ ${ }^{16}$ Air Chemistry Group of the Hungarian Academy of Sciences, University of Pannonia, P.O. Box 158, \\ 8201 Veszprém, Hungary \\ ${ }^{17}$ Netherlands Organisation for Applied Scientific Research TNO, Princetonlaan 6, 3508 TA Utrecht, The Netherlands \\ ${ }^{18}$ National Centre for Atmospheric Science, School of Geography, Earth and Environmental Sciences, University of \\ Birmingham, B15 2TT, UK \\ ${ }^{19}$ National University of Ireland Galway, University Road, Galway, Ireland \\ ${ }^{20}$ German Meteorological Service, Hohenpeienberg Observatory, Albin-Schwaiger Weg 10, \\ 82383 Hohenpeißenberg, Germany \\ ${ }^{21}$ German Federal Environment Agency (UBA), Messnetzzentrale, Langen, Germany
}

Received: 23 February 2011 - Published in Atmos. Chem. Phys. Discuss.: 16 March 2011

Revised: 25 May 2011 - Accepted: 26 May 2011 - Published: 15 June 2011

\section{Abstract.}

Two years of harmonized aerosol number size distribution data from 24 European field monitoring sites have been analysed. The results give a comprehensive overview of the European near surface aerosol particle number concentrations

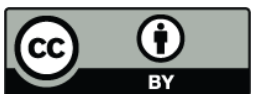

Correspondence to: A. Asmi (ari.asmi@ helsinki.fi) and number size distributions between 30 and $500 \mathrm{~nm}$ of dry particle diameter. Spatial and temporal distribution of aerosols in the particle sizes most important for climate applications are presented. We also analyse the annual, weekly and diurnal cycles of the aerosol number concentrations, provide log-normal fitting parameters for median number size distributions, and give guidance notes for data users. Emphasis is placed on the usability of results within the aerosol modelling community.

Published by Copernicus Publications on behalf of the European Geosciences Union. 
We also show that the aerosol number concentrations of Aitken and accumulation mode particles (with $100 \mathrm{~nm}$ dry diameter as a cut-off between modes) are related, although there is significant variation in the ratios of the modal number concentrations. Different aerosol and station types are distinguished from this data and this methodology has potential for further categorization of stations aerosol number size distribution types.

The European submicron aerosol was divided into characteristic types: Central European aerosol, characterized by single mode median size distributions, unimodal number concentration histograms and low variability in $\mathrm{CCN}$-sized aerosol number concentrations; Nordic aerosol with low number concentrations, although showing pronounced seasonal variation of especially Aitken mode particles; Mountain sites (altitude over $1000 \mathrm{~m}$ a.s.l.) with a strong seasonal cycle in aerosol number concentrations, high variability, and very low median number concentrations. Southern and Western European regions had fewer stations, which decreases the regional coverage of these results. Aerosol number concentrations over the Britain and Ireland had very high variance and there are indications of mixed air masses from several source regions; the Mediterranean aerosol exhibit high seasonality, and a strong accumulation mode in the summer. The greatest concentrations were observed at the Ispra station in Northern Italy with high accumulation mode number concentrations in the winter. The aerosol number concentrations at the Arctic station Zeppelin in Ny-Ålesund in Svalbard have also a strong seasonal cycle, with greater concentrations of accumulation mode particles in winter, and dominating summer Aitken mode indicating more recently formed particles. Observed particles did not show any statistically significant regional work-week or weekday related variation in number concentrations studied.

Analysis products are made for open-access to the research community, available in a freely accessible internet site. The results give to the modelling community a reliable, easy-touse and freely available comparison dataset of aerosol size distributions.

\section{Introduction}

Atmospheric aerosols have multiple effects on climate, air quality, human health and atmospheric visibility (e.g. Charlson, 1969; Horvath, 1993; Laden et al., 2006; Lohmann and Feichter, 2005; Pope and Dockery, 2006; Stevens and Feingold, 2009). To understand the effects of aerosol particles on climate and health, measurements of their chemical and physical properties, e.g. size distributions and concentrations in the atmosphere, are needed. Several European campaigntype projects have provided important information on the atmospheric aerosol properties in Europe, usually by concentrating on specific aerosol problems e.g. PARFORCE on new
Table 1. Nomeclature

\begin{tabular}{|c|c|c|}
\hline Symbol & meaning & unit \\
\hline$d_{p}$ & electrical mobility particle diameter & $\mathrm{nm}$ \\
\hline$\hat{d_{p}}$ & $\begin{array}{l}\text { nominal (mean) diameter of measured } \\
\text { size interval }\end{array}$ & $\mathrm{nm}$ \\
\hline$n$ & $\begin{array}{l}\text { number concentration (of a size range } \\
\text { or a interval) }\end{array}$ & $\mathrm{cm}^{-3}$ \\
\hline$\frac{d n\left(d_{p}\right)}{d \log _{10} d_{p}}$ & size distribution function & $\mathrm{cm}^{-3}$ \\
\hline$N_{30-50}$ & $\begin{array}{l}\text { aerosol number concentration between } \\
30 \text { and } 50 \mathrm{~nm}\end{array}$ & $\mathrm{~cm}^{-3}$ \\
\hline$N_{50}$ & $\begin{array}{l}\text { aerosol number concentration between } \\
50 \text { and } 500 \mathrm{~nm}\end{array}$ & $\mathrm{~cm}^{-3}$ \\
\hline$N_{100}$ & $\begin{array}{l}\text { aerosol number concentration between } \\
100 \text { and } 500 \mathrm{~nm}\end{array}$ & $\mathrm{~cm}^{-3}$ \\
\hline$N_{250}$ & $\begin{array}{l}\text { aerosol number concentration between } \\
250 \text { and } 500 \mathrm{~nm} \text { (Appendix B) }\end{array}$ & $\mathrm{cm}^{-3}$ \\
\hline $\bar{x}$ & Arithmetic mean of $x$ & same as $x$ \\
\hline$\hat{x}$ & Geometric mean of $x$ & same as $x$ \\
\hline$\mu_{p}(x)$ & p-th percentile of $x$ & same as $x$ \\
\hline$\sigma(x)$ & (linear) standard deviation of $x$ & same as $x$ \\
\hline$\sigma_{l}(x)$ & 10-logarithmic standard deviation of $x$ & - \\
\hline$A 1(x)$ & Autocorrelation (1-h) of $x$ & - \\
\hline
\end{tabular}

particle formation in the marine environment (O'Dowd et al., 2002), BIOFOR for biogenic aerosol production (Kulmala et al., 2001), or ACE-2 for aerosol-cloud interactions (Raes et al., 2000). However, this kind of information is sensitive to the representativeness of the data on temporal and often also on spatial scales.

The EUSAAR (European Supersites for Atmospheric Aerosol Research) project of the Sixth Framework Programme of the European Commission is one of the steps towards a reliable and quality-controlled network of measurements (Philippin et al., 2009). The EUSAAR project has improved and homogenized 20 European sites for measuring aerosol chemical, physical and optical properties following a standardized protocol of instrument maintenance, measurement procedures and data delivery in common format to a common data base (Wiedensohler et al., 2010). EUSAAR also provided intercomparison and calibration workshops as well as training for the station operators. The improvements in EUSAAR stations have already proven to be extremely useful in other European aerosol-related projects, such as EUCAARI (Kulmala et al., 2009). The German Ultrafine Aerosol Network (GUAN) is a network of multiple German institutes with an interest on submicron aerosol properties (Birmili et al., 2009a), which has been established in 2008. The methodologies of number size distribution measurements and data handling procedures in both GUAN and EUSAAR networks are very similar and the size distribution measurements results are comparable between the two networks. 
Users of field experiment data may not be experts on the measurement techniques, or be aware of the typical error sources of experimental atmospheric data. Knowledge on e.g. how the measurements were made, or which kind of data are usable for different purposes are questions which are not always clearly answered in all experimental datasets. The use of the data requires very close co-operation with the experimentalist providing the data - a step not always easy to do and sometimes regrettably overlooked by data users.

This article provides an easy-to-use reference on aerosol number concentrations and size distributions for dry diameters between 30 and $500 \mathrm{~nm}$ for the years 2008 and 2009 at the EUSAAR and GUAN stations. We present number concentrations of different aerosol size ranges and study the diurnal, weekly and seasonal variability of aerosol number concentrations at the stations. The analysis focuses on particle sizes with most potential for climate applications.

\subsection{Relevant metrics and properties of sub-micron size distributions}

The intent of this article is to produce relevant metrics describing the aerosol number size distributions observed at 24 EUSAAR and GUAN stations. Almost all stations have comparable size distribution measurements in dry particle diameters between 30 and 500 nanometres, and thus we limit our analysis to this size range only.

The aerosol-climate effects are divided into two groups. The direct effect represents the ability of the particle population to absorb and scatter short-wave radiation - directly affecting the radiation balance. These direct effects depend primarily on the aerosol optical properties and particle size distribution (Haywood and Boucher, 2000; Charlson et al., 1992). The indirect effects climate through the effects of aerosol particles on clouds and is commonly concerned with cloud albedo (or Twomey) effect and cloud lifetime effect. The cloud albedo effect is the resulting change in cloud radiative properties due to changes in cloud droplet number number concentration (CDNC); The lifetime effect is connected to the changes in cloud properties and in drizzle and precipitation (Twomey, 1974; Albrecht, 1989; Lohmann and Feichter, 2005).

The aerosol indirect effect is controlled by the ability of particles to activate to cloud droplets (i.e. Cloud Condensational Nuclei, $\mathrm{CCN}$ ) within a cloud (Andreae and Rosenfeld, 2008). This ability is a strong function of particle size, water supersaturation, and particle hygroscopicity (chemical composition) (Lohmann and Feichter, 2005; McFiggans et al., 2006). An extensive overview of most of these effects are provided in McFiggans et al. (2006), who specified the particle size as the most important pre-requisite to get the activated fraction of particles correct. We consider the aerosol size as the dominating factor for aerosol particle potential to act as $\mathrm{CCN}$, and thus the proxies of potential $\mathrm{CCN}$ are produced using only aerosol number size distribution data.
The representative minimum dry diameter for $\mathrm{CCN}$ activation is often considered to be between 30 to over $100 \mathrm{~nm}$, depending on particle composition, used water supersaturation and other factors (e.g. Dusek et al., 2006; Kerminen et al., 2005; Andreae and Rosenfeld, 2008). In modelling studies, representative $\mathrm{CCN}$ numbers are often calculated directly from dry aerosol size spectrum using a nominal cut-off diameter, such as $70 \mathrm{~nm}$ (Spracklen et al., 2005; Makkonen et al., 2009) or $50 \mathrm{~nm}$ (Pringle et al., 2009). The CCNs are not, however, linearly connected to CDNCs, as the water depletion and other cloud processes can increase the actual cut-off diameter of cloud activation. In field experiments done at the top of mountains, a semi-direct measurement of the activated fraction to CDNC can be sometimes made, with activation diameters observed from $40 \mathrm{~nm}$ to over $200 \mathrm{~nm}$ (Henning et al., 2002; Sellegri et al., 2003; Lihavainen et al., 2008). Nevertheless, fixed activation diameters have been used as surrogates in several CCN-to-CDNC parameterizations (e.g. Jones et al., 1994; Lin and Leaitch, 1997).

The controlling variable for aerosol indirect effect is usually considered to be the number of particles activated. Particle number concentrations are usually dominated by particles with dry diameters less than $500 \mathrm{~nm}$. We approximate the $N_{50}$ and $N_{100}$ concentrations by integrating the size distribution to $d_{p}=500 \mathrm{~nm}$ :

$$
N_{50}(t) \approx \sum_{\hat{d}_{p}=50 \mathrm{~nm}}^{500 \mathrm{~nm}} n_{i}\left(\hat{d}_{p}, t\right)
$$

and

$$
N_{100}(t) \approx \sum_{\hat{d}_{p}=100 \mathrm{~nm}}^{500 \mathrm{~nm}} n_{i}\left(\hat{d}_{p}, t\right)
$$

where $\hat{d}_{p}$ is the geometric mean diameter of the size interval and $n_{i}$ is the measured aerosol number concentration in the size interval $\left(\mathrm{cm}^{-3}\right)$. The $N_{50}$ and $N_{100}$ concentrations present two proxies for $\mathrm{CCN}$-sized aerosol number concentrations. Figure 1 shows graphically the size ranges used in the analyses. Note that the regions overlap for particle diameters larger than $100 \mathrm{~nm}$, and thus $N_{100}(t) \leq N_{50}(t), \forall t$. The cut-off diameters of 50 and $100 \mathrm{~nm}$ correspond roughly to critical supersaturations of $0.8 \%$ and $0.3 \%$ for Finnish background aerosol (Sihto et al., 2010, $\kappa=0.18$ ) and $0.4 \%$ and $0.15 \%$ for pure ammonium nitrate particles (Petters and Kreidenweis, 2007, $\kappa=0.67)$. In high-CCN concentration regions there is a need for a proxy for even larger sized CCNs, and we have also calculated similar factor for particles larger than $250 \mathrm{~nm}$ diameter $\left(N_{250}\right)$. The results, potential error sources and discussion of $N_{250}$ concentrations are shown in Appendix B.

From the above discussion, it is obvious that number concentrations of particles with dry diameters larger than $50 \mathrm{~nm}$ are critical to the climate effects of particles. There are, however, reasons to study particles with smaller diameters. 
Particles with $d_{p}<100 \mathrm{~nm}$ have been widely acknowledged to have potential for adverse health effects (e.g. Donaldson et al., 1998; Hoet et al., 2004; Sager and Castranova, 2009), although the knowledge which particles property is most important for health effects has not yet determined (Wittmaack, 2007, and related online correspondence). The particle deposition to alveolar region of lungs is assumed to be especially efficient for particles of diameters between $10-50 \mathrm{~nm}$ (Oberdörster et al., 2005).

Another reason to study the sub-50 $\mathrm{nm}$ particles is related to aerosol particle dynamics in atmosphere. By providing a parameter for the smaller size ranges in the atmosphere, we can take into account smaller particles generated from new particle formation and combustion sources. This provides an additional parameter for model-measurement comparisons and a larger part of the particle spectrum and additional particle processes can be taken into account. We describe a concentration $N_{30-50}$ as the number concentration of particles from $30 \mathrm{~nm}$ to $50 \mathrm{~nm}$ as

$N_{30-50}(t)=\sum_{\hat{d}_{p}=30 \mathrm{~nm}}^{50 \mathrm{~nm}} n_{i}\left(\hat{d}_{p}, t\right)$

where the smaller diameter limit of $30 \mathrm{~nm}$ comes mainly from instrumental and site-related limitations and from trying to limit the effect of actual new particle formation events to variance. Particles and ions smaller than $30 \mathrm{~nm}$ dry diameter were studied in detail by Manninen et al. (2010), using instrumentation designed and calibrated for extremely small particle diameters (Asmi et al., 2009).

Comparisons between measured and modelled concentrations have usually been done using the arithmetic means of the relevant quantities. We will show that at many stations concentration histograms are slightly skewed log-normal distributions. A typical arithmetic mean comparison is of less use for these distributions, as the values of linear means are strongly affected by the outlier values. A way to compare the results would then be the ability of a model to reproduce the measured concentration histograms. We consider in this article mostly the percentile values of the number size distribution to represent the histogram - simultaneously showing a comparable mean value (median of the distribution) and some indication of the histogram shape and the concentration variance (other percentiles). For practical reasons, most of the percentile values shown are presented in this article only for the three middle percentile values (16th, 50th and 84th) - although the 5th and 95th percentile values are available in the comparison database (see Sect. 4.5).

\section{Methods}

\subsection{Station descriptions}

Data from 24 stations are used in this study; 18 are EUSAAR stations, 5 are from German GUAN network and one is a joint EUSAAR-GUAN station.

\subsubsection{EUSAAR -European Supersites for Atmospheric Aerosol Research}

EUSAAR is a EU-funded I3 (Integrated Infrastructures Initiatives) project carried out in the framework of the specific research and technological development programme "Structuring the European Research Area - Support for Research Infrastructures". It coordinates and harmonizes aerosol measurements at 20 stations across Europe (see Fig. 2), 19 of which are included in this study. All of the EUSAAR stations are also EMEP/GAW joint super sites.

The regional background station Aspvreten is located in Sörmland, some $70 \mathrm{~km}$ south west of Stockholm. The station is situated about $2 \mathrm{~km}$ from the coast in a rural area covered by mixed coniferous and deciduous forest with some meadows. The influence from local anthropogenic activities is small, and the area around the station is sparsely populated. The station is operated by the Department of Applied Environmental Science (ITM), Atmospheric Science unit. The station is considered to be representative of the regional background in Mid-Sweden.

The Birkenes Observatory (BIR) is located in Southern Norway and is run by NILU - Norwegian Institute for Air Research. The terrain is undulating and the site is located in a clearing with relatively free exposure to exchange of air masses by wind, and with low local sources or pollution. The station was moved to a nearby similar location in 2009, and the data from July-December 2009 were from the new station located in $58^{\circ} 23^{\prime} 18^{\prime \prime} \mathrm{N} 8^{\circ} 15^{\prime} 7^{\prime \prime} \mathrm{E}, 219 \mathrm{~m}$ a.s.l.

The station Pallas (PAL) is run by the Finnish Meteorological Institute. PAL is located on a top of a treeless hill in a remote continental area at the northern border of the boreal forest zone in Europe. The station receives polluted European air masses, but also clean marine air from the Arctic with very little continental influence. The frequent presence of clouds allows measurements of cloud microphysical parameters and, during intensive campaigns, cloud chemical parameters. The direct aerosol effect results from a combination of aerosol absorption and scattering. The particle absorption is primarily controlled by the amount of absorbing compounds in the particle (e.g. Horvath, 1993). Aerosol scattering is strongly connected to particle surface area and refractive indices and is thus not easy to simulate from size distribution data. The Preila environmental pollution research station (PLA) is located in western Lithuania at the coast of the Baltic Sea, on the Curonian Spit. The station is operated by Center for Physical Sciences and Technology, Lithuania. This monitoring site was selected according to strict criteria designed to avoid undue influence from point sources, area sources and local activities.

The SMEAR II station (Station for Measuring Forest Ecosystem-Atmosphere Relations) in Hyytiälä ( $220 \mathrm{~km} \mathrm{NW}$ from Helsinki) is run by the University of Helsinki, Finland. 


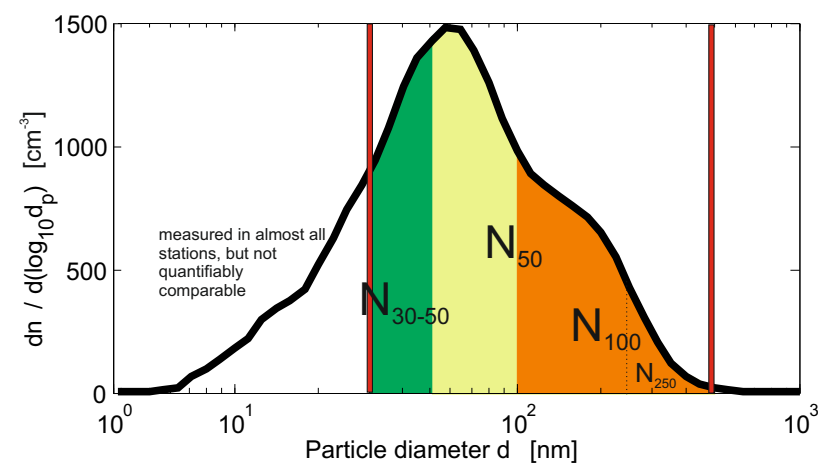

Fig. 1. Size regions used in the analysis. The red lines show the size cut-offs from $30 \mathrm{~nm}$ to $500 \mathrm{~nm}$. The green area shows the region used to calculate $N_{30-50}$, the orange area $N_{100}$ and the total area of orange and teal are the $N_{50}\left(N_{100}\right.$ is part of $\left.N_{50}\right) . \quad N_{250}$ concentration (Appendix B) is shown in dotted line.

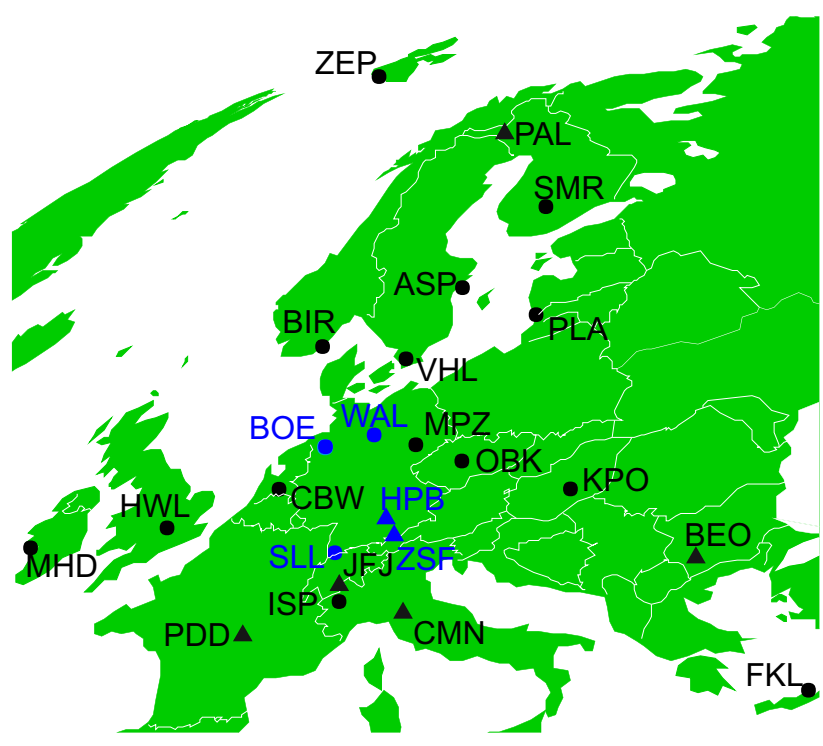

Fig. 2. Geographic distribution of stations used in this article. EUSAAR stations are marked with black and GUAN stations in blue. Station MPZ belongs also to the GUAN network. Circles denote boundary layer sites and triangles sites of relatively high altitude. See Table 2 for stations' codes.

It includes several measurement towers, and a cottage for instruments and computers. The air quality at the site is considered to represent typical regional background conditions for higher latitudes of Europe. The air masses are influenced by European pollution but at times very clean Arctic air is observed. The station is located within a Scots pine stand.

The station of Vavihill (VHL) is operated since 1984, and additional laboratory facilities and aerosol equipment were installed by Lund University starting 1999 . VHL is a continental regional background site with no local sources of pollution, situated in the southernmost part of Sweden. It is well-suited for studies of the influx of polluted air from continental Europe to the Nordic countries along a south-north transect.

The K-puszta station (KPO) is run by the Hungarian Meteorological Service and University of Vezprem. The sampling site is relatively far from anthropogenic sources, it is $80 \mathrm{~km}$ from Budapest in the SE direction and the largest nearby town is about $15 \mathrm{~km} \mathrm{SE}$ from the station. Samples collected at K-puszta are considered to be representative of the Central-Eastern European regional conditions.

The Observatory Kosetice (OBK) is a regional background monitoring station run by the Czech Hydrometeorological Institute within the national Air Quality monitoring network. The aerosol measurements are carried out by ICPF. The observatory is located in agricultural countryside outside of major population centres in the southern part of the Czech Republic far from local source of pollution.

BEO Moussala (BEO) is run by the Bulgarian Academy of Science. Because of the high elevation of the mountain observatory and because BEO is located far from any local source of pollution, the air is considered to be representative of synoptic scale atmospheric composition of the natural free-tropospheric background (Nojarov et al., 2009).

The Cabauw Experimental Site for Atmos. Res. CESAR $(\mathrm{CBW})$ is situated in an agricultural area in the western part of The Netherlands, $44 \mathrm{~km}$ from the North Sea, in the vicinity of cities such as Amsterdam, The Hague, Rotterdam and Utrecht, and near major highways. Hence a variety of air masses can be encountered from modified clean maritime to continental polluted. The aerosol measurements used in this paper are done by TNO.

The Finokalia station (FKL) is run by the Environmental Chemical Processes Laboratory (ECPL) of the University of Crete. The FKL station is located in the SE Mediterranean on the island of Crete. It is located far from local sources of pollution, facing the sea within a sector $270^{\circ}$ to $90^{\circ}$ and the air is considered to be representative of synoptic scale atmospheric characteristics.

The Harwell Station (HWL) is operated by the University of Birmingham, primarily on behalf of the Department for Environment, Food and Rural Affairs (DEFRA) as a rural station representative of large scale air masses affecting Southern England. There are however, periods of easterly winds where it is directly in the plume from London (approx $80 \mathrm{~km}$ distance) and there are very marked differences between air composition from easterly and westerly trajectories (Charron et al., 2008).

The high Altitude Research Station Jungfraujoch (JFJ) is operated by the International Foundation High Altitude Research Stations Jungfraujoch and Gornergrat and is part of numerous networks. The aerosol measurements are done by PSI. JFJ is located far from local sources and is well suited to determine the regional background above a continental area. 
Table 2. Locations and names of stations used in the data analysis. The site altitudes are given in reference to standard sea level. The areas indicated are grouped by European sub-divisions using definitions from Central Intelligence Agency (2009). Country codes are given in ISO 3166 standard.

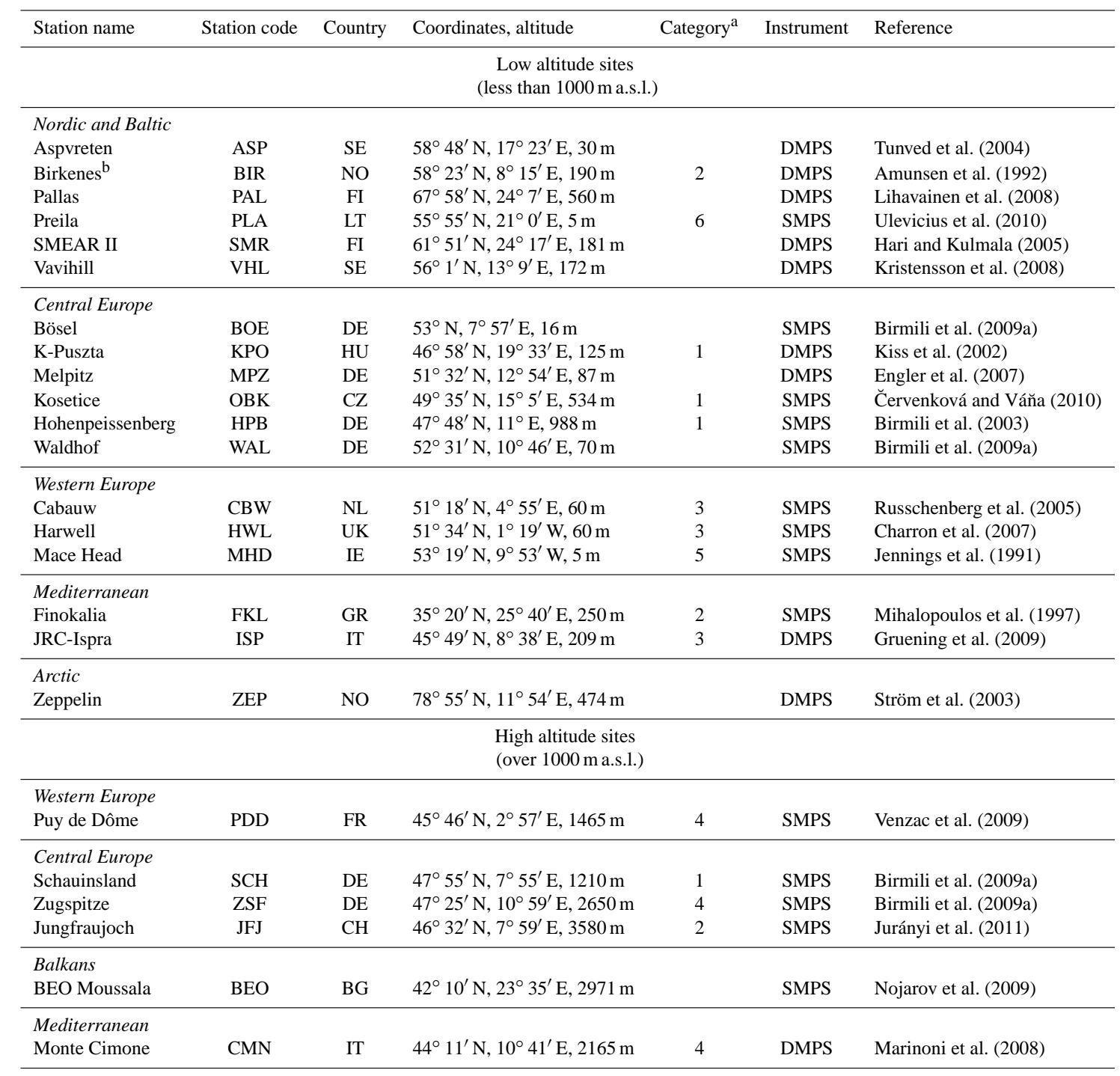

a Station representativeness classification from Henne et al. (2010) (if available):

(1) Rural; (2) Mostly remote; (3) Agglomeration; (4) Weakly influenced; (5) Generally remote; (6) Weakly influenced, generally remote ${ }^{\mathrm{b}}$ Station was moved in summer 2009 to location $58^{\circ} 23^{\prime} \mathrm{N} 8^{\circ} 15^{\prime} \mathrm{E}, 219 \mathrm{~m}$ a.s.l.

Since the station is within clouds 40 percent of the time, aerosol - cloud interactions can be studied as well.

The JRC-Ispra atmospheric research station (ISP) is run by the Institute for Environment and Sustainability of the EC - DG Joint Research Centre. ISP is located a tens of kms from local sources of pollution and is generally representative of the regional (quite polluted) atmospheric regional background.

The atmospheric research station Mace Head (MHD) is a major facility of the National University of Ireland, Galway and is managed through the Mace Head Management Committee. MHD is GAW global baseline station a designated EMEP supersite. MHD has open exposure to the North Atlantic ocean and is considered to be representative of relatively clean background marine air, although it encounters some anthropogenic pollution events.

Melpitz (MPZ) is an atmospheric research station in Eastern Germany, $40 \mathrm{~km}$ northeast of Leipzig. The station is surrounded by flat and semi-natural grasslands without any obstacles, as well as agricultural pastures and forests in the 
wider environment. Atmospheric observations at MPZ can be regarded as representative of regional background conditions in Central Europe, as shown by a multiple-site comparison within the GUAN (Birmili et al., 2009a). The air masses observed at MPZ tend to partition into Atlantic (westerly) air masses with low particle mass concentrations, and continental (easterly) air masses with high particle mass concentrations (Engler et al., 2007; Spindler et al., 2010). MPZ is part of the EUSAAR and GUAN networks.

The "O. Vittori" Station at Monte Cimone (CMN), hosted in a military site of the Italian Air Force, is run by ISAC-CNR and is part of GAW. Monte Cimone is the highest peak of the Northern Italian Apennines (2165 m a.s.l.), characterized by a $360^{\circ}$ free horizon. It is located south of the Po Basin and is a strategic platform to study chemical and physical characteristics of regional background conditions and air mass transport. The measurements of atmospheric compounds carried out at CMN can be considered representative of the South European and North Mediterranean free troposphere (Fischer et al., 2003). Nevertheless, due to enhanced vertical mixing and a mountain breeze wind regime, during the warm months an influence from the lowest layer of the troposphere cannot be ruled out (Marinoni et al., 2008; Cristofanelli et al., 2007).

The Puy de Dôme station (PDD) is run by OPGC/CNRSLaMP and is located a few tens of km from ClermontFerrand, France, in the Massif Central mountain chain. Due to its high altitude ( $1465 \mathrm{~m}$ a.s.l) the air mass composition is representative of the regional atmospheric background during the day and more representative of larger synoptic-scale air masses during night-time.

The Zeppelin Observatory in Ny-Ålesund (ZEP) at Svalbard is owned and operated by the Norwegian Polar Institute. NILU is responsible for the scientific programmes at the station, as part of the largest Arctic research infrastructure. The ongoing monitoring is performed in cooperation with Stockholm University (SU). The site is located in an undisturbed Arctic environment. Zeppelin Mountain is an excellent site for atmospheric monitoring, with minimal contamination from the local settlement due to its location above the inversion layer. ZEP is a global GAW site.

\subsubsection{GUAN - German Ultrafine Aerosol Network}

The German Ultrafine Aerosol Network (GUAN; Birmili et al., 2009a) is a cooperation of federal and state-based environment agencies as well as research institutes. Under the umbrella of the German Federal Environment Agency (UBA), GUAN investigates the sources, atmospheric processes as well as climatological and health effects related to ultrafine aerosol particles and soot over Germany. To date, GUAN conducts particle number size distribution and soot measurements at 14 measurement stations across Germany. The range of sites in GUAN spans remote regional background, rural regional background, urban, as well as roadside observation sites. In this article, we use measurement data only from five rural regional background stations in GUAN. One of them, MPZ, is a joint station of EUSAAR and GUAN and was described above.

Bösel (BOS) is a regular site in the government air quality monitoring system of Lower Saxony (LÜN, Staatliches Gewerbeaufsichtsamt Hildesheim). To the south, the sampling site borders agricultural pastures while to the north, it touches some residential areas of the village of Bösel. Some noticeable features of the site include its location in an area of intense livestock production (including enhanced ammonia emissions), and the limited distance from the North Sea coast $(100 \mathrm{~km})$.

Waldhof (WAL) is a measurement station of the German Federal Environment Agency (UBA). The site is located in the biggest north German forest and heath environment (Lüneburger Heide) and is therefore only very little influenced by local anthropogenic sources. Measurements here are considered to be representative of the remote regional background in the North German lowlands. The nearest larger cities are Hanover and Hamburg. WAL is also an EMEP station and a regional GAW site.

Schauinsland (SSL) is another key measurement station of the German Federal Environment Agency (UBA), with atmospheric composition measurements dating back to 1967 . The station is situated on a mountain ridge in the Black Forest, southwest Germany. SSL is located more than $1000 \mathrm{~m}$ above the upper Rhine river valley, where pollution sources are ubiquitous. As is usual for a mid-level mountain station, boundary layer dominates during the day, while at night especially in winter, the station often resides above the surface inversion. The station is well-suited to characterize air masses that approach Central Europe from westerly directions. SSL is also an EMEP station.

Hohenpeissenberg (HPB) is a climate observatory of the German Meteorological Service (DWD) hosting a wide range of atmospheric in-situ and remote sensing observations. HPB is also a GAW station. The site is located on an isolated mountain, about $60 \mathrm{~km}$ south of Munich, and about $40 \mathrm{~km}$ north of Zugspitze, Germany's highest elevation on the northern edge of the Alps. Separated from the surrounding countryside by an elevation difference of $300 \mathrm{~m}$, the HPB site avoids immediate contamination by nearby anthropogenic sources.

Zugspitze-Schneefernerhaus (ZSF) is the highest mountain of the German Alps. It is located in Southern Germany, about $90 \mathrm{~km}$ southwest of Munich, at the Austrian border near the town of Garmisch-Partenkirchen. The GAW monitoring program is operated jointly by the Federal Environmental Agency (UBA) and the German Meteorological Service (DWD). Its high altitude causes an annual cycle in aerosol particle number and mass concentration as a result of different different boundary layer heights in summer and winter (Birmili et al., 2009b). The Zugspitze's elevated position allows characterisation of air masses that had only little 
contact with the local boundary layer, and may therefore be representative of a very large continental area.

\subsection{Instrumentation}

Two types of instruments for measuring ultrafine particle size distributions were used to obtain the results presented in this article: The Differential Mobility Particle Sizer (or DMPS), and the Scanning Mobility Particle Sizer (SMPS). Both are very similar instruments in their operation: they aspirate dried air, use ionizing radiation to establish an equilibrium bipolar charge-distribution in the sampled aerosol (Wiedensohler, 1988), use a cylindrical differential mobility analyser to select particles based on their electrical mobility and use a condensation nuclei counter to measure the resulting concentrations in each of the selected size ranges (McMurry, 2000; Laj et al., 2009; Wiedensohler et al., 2010). The main difference between these instruments is the mode of operation, as the DMPS keeps the differential mobility analyser voltage constant during measurement of a single size interval and the SMPS scans with continuously differing voltages. The size range and time resolution of a DMPS or a SMPS system depends on the system architecture (e.g. the physical dimensions of the instrument and the flow rates used) and on user choice (more size channels vs. faster scanning).

\subsubsection{Uncertainty of mobility size spectrometer measurements}

Two aspects have to be considered determining the uncertainty of particle number size distributions. First, as known from intercomparison in the past (Khlystov et al., 2001; Dahmann et al., 2001; Imhof et al., 2006; Helsper et al., 2008) and the EUSAAR calibration workshops Wiedensohler et al. (2010), the unit-to unit variability between mobility size spectrometer can be up to $25 \%$ in the size range $20-500 \mathrm{~nm}$. The instruments used at the EUSAAR stations performed were within $10 \%$ for the size range $20-200 \mathrm{~nm}$ against the EUSAAR reference system under controlled laboratory conditions, while for sizes up to $500 \mathrm{~nm}$ the deviation was up to $25 \%$. The overall $N_{100}$ concentrations are usually within 10 $\%$ of the reference instrument (Fig. 7 of Wiedensohler et al., 2010). This data were achieved after averaging ambient measurements of a time period of few hours. Additionally, a short term variation due to aerosol flow instability might be up to $5 \%$ depending on the internal flow control. These variations between the instruments and the short term variability (stability) of the instruments should be taken into account when drawing conclusions on the variabilities and differences between aerosol number size distributions.

\subsubsection{General comments on aerosol properties}

Particle diameter. In this article particle we use electrical mobility diameter $d_{p}$, which is defined as the diameter where the electrostatic force of a (single) charged particle
Table 3. Definition of seasons used in analysis given as Day of Year. Note that 2008 was a leap year.

\begin{tabular}{llrr}
\hline Season & Months & DOY 2008 & DOY 2009 \\
\hline Winter & Dec, Jan, Feb & $1-60,336-366$ & $1-59,335-365$ \\
Spring & Mar, Apr, May & $61-152$ & $60-151$ \\
Summer & Jun, Jul, Aug & $153-244$ & $152-243$ \\
Autumn & Oct, Sep, Nov & $244-335$ & $243-334$ \\
\hline
\end{tabular}

in the electrical field is identical to the drag force including the Cunningham correction (Hinds, 1999). The choice of this diameter comes naturally from the experimental set-up, as the size-resolving instruments in this paper (SMPS and DMPS) use electrical mobility diameter as the basis of their size-selection. The most important feature of this diameter is that for spherical particles the electrical mobility diameter is identical to the geometric diameter. For DMPS and SMPS data, the actually reported diameter is usually the intervalaverage diameter $\hat{d}_{p}$, which is the geometric mean diameter of the size interval used in the DMPS or SMPS inversion.

The number concentration is defined as the number of aerosol particles in a 1 cubic centimetre $\left(10^{-6} \mathrm{~m}^{-3}\right)$ volume of air at $\mathrm{STP}^{1}$. The difference from the actual environmental situation on-site can be significant especially for mountain sites. The size spectra are reported, both in databases and in size distribution figures of this article, as a particle number size distribution function $\frac{d n\left(d_{p}\right)}{d \log _{10} d_{p}}$. This function provides comparable size spectra even thought the widths of intervals are different in different instruments.

The measured aerosol properties are measured for $d r y$ aerosol samples. The sample air is dried to relative humidity $\mathrm{RH} \leq 40 \%$ before size selection.

The results are categorized by season. We divided the seasons according to the calendar year as indicated in Table 3. This selection is arbitrary, but should show the main meteorological and seasonal variations observed in the datasets and provides a way to compare the results with short-term simulations as done with regional Chemical Transport Models (CTMs).

\subsubsection{Data handling}

The processing of raw data to physical quantities is detailed in Wiedensohler et al. (2010). The data inversion and prescreening were done by the institutes operating the instruments. The data was flagged for instrument failure or maintenance breaks. Other important features related to the mea-

\footnotetext{
${ }^{1}$ EUSAAR and GUAN follow GAW (Global Atmosphere Watch) recommendation for STP. The STP air is defined to be $T=293.15 \mathrm{~K}, P=101300 \mathrm{~Pa}$ (WMO/GAW, 2003).
} 
Table 4. Mean values of the station concentrations. $\bar{n}$ is the arithmetic mean concentration in the size section in question, $\hat{n}$ is the geometric mean concentration and the $\mu_{x}$ values are the $\mathrm{x}$-th percentage of the concentration distribution. $\mu_{50}$, or median value, is bolded. All concentrations are in $\left[\mathrm{cm}^{-3}\right]$. Refer to Sect. 2.2.1 for details on instrumental uncertainties.

\begin{tabular}{|c|c|c|c|c|c|c|c|c|c|c|c|c|c|c|c|c|c|c|c|c|c|c|}
\hline \multirow[b]{2}{*}{ Station } & \multirow[b]{2}{*}{ Code } & \multicolumn{7}{|c|}{$N_{30-50}$ concentration $\left[\mathrm{cm}^{-3}\right]$} & \multicolumn{7}{|c|}{$N_{50}$ concentration $\left[\mathrm{cm}^{-3}\right]$} & \multicolumn{7}{|c|}{$N_{100}$ concentration $\left[\mathrm{cm}^{-3}\right]$} \\
\hline & & $\bar{n}$ & $\hat{n}$ & $\mu_{05}$ & $\mu_{16}$ & $\mu_{50}$ & $\mu_{84}$ & $\mu_{95}$ & $\bar{n}$ & $\hat{n}$ & $\mu_{05}$ & $\mu_{16}$ & $\mu_{50}$ & $\mu_{84}$ & $\mu_{95}$ & $\bar{n}$ & $\hat{n}$ & $\mu_{05}$ & $\mu_{16}$ & $\mu_{\mathbf{5 0}}$ & $\mu_{84}$ & $\mu_{95}$ \\
\hline Aspvreten & ASP & 397 & 2 & 72 & 1 & 2 & 662 & 1 & 234 & 959 & 24 & 461 & 1001 & 1992 & 2751 & 543 & 396 & 97 & 181 & 421 & 904 & 1362 \\
\hline Birkenes & BIR & & 146 & 27 & 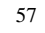 & 156 & 393 & & & 443 & 65 & 156 & 511 & 1288 & & 327 & 202 & 38 & 69 & 218 & 583 & 1007 \\
\hline Pallas & PAL & 198 & 8 & 12 & 25 & 89 & 345 & & & 187 & 20 & 53 & 205 & 769 & 13 & 211 & 80 & $J$ & 20 & 111 & 402 & 782 \\
\hline Preila & PLA & 1042 & 564 & 120 & 236 & 610 & 1386 & 2272 & 3581 & 2233 & 48 & 1042 & 2527 & 4741 & & 2030 & 1149 & 256 & 466 & 1303 & 2490 & 4407 \\
\hline SMEAR & SMR & & 213 & 41 & 85 & 223 & & & & & & & 878 & 1 & & 450 & 320 & 76 & 141 & 11 & & 156 \\
\hline Vavihill & VHL & & 3 & 9 & 1 & 4 & & 1 & 1 & 1231 & 36 & 6 & 1368 & 24 & & & 490 & 1 & 2 & 7 & 41 & 471 \\
\hline Bösel & BOS & 1314 & 1088 & 4 & 62 & 1122 & 1909 & 292 & 2973 & 2417 & 69 & 1294 & 2679 & 4569 & 62 & 28 & 1108 & 27 & 539 & 1250 & 07 & 3222 \\
\hline K-Pusz & KPO & 979 & 87 & 2 & 3 & 6 & 1414 & 27 & 3669 & 2992 & 1098 & 1764 & 3120 & 56 & 80 & 1952 & 1580 & 53 & 901 & 1660 & 76 & 4366 \\
\hline Koset & BK & 58 & 887 & 2 & 38 & 71 & 1428 & 257 & 3518 & 2900 & 1098 & 1791 & 3194 & 51 & 69 & 2058 & 1687 & 606 & 1029 & 1863 & 54 & 4112 \\
\hline Hohenpe & HPB & 02 & 405 & 1 & 22 & 407 & 735 & 11 & 1418 & 1131 & 29 & 556 & 1325 & 2200 & 29 & 792 & 594 & 116 & 260 & 739 & 70 & 1657 \\
\hline Melpitz & MPZ & 1187 & 801 & 22 & 42 & 860 & 1634 & 323 & 2681 & 2179 & 72 & 1222 & 2327 & 4078 & 59 & 1487 & 1193 & 363 & 62 & 1304 & 2324 & 3271 \\
\hline Waldl & $\mathrm{AL}$ & & & & 43 & & 1715 & 282 & 2749 & 2234 & 69 & 1157 & 2434 & 42 & & 341 & 1081 & 31 & & 1189 & & 2860 \\
\hline Cabauw & BW & 2137 & 1642 & 373 & 846 & 1914 & 3401 & 4599 & 2910 & 2883 & 568 & 1290 & 3387 & 6487 & 91 & 1240 & 845 & 159 & 3 & 952 & 2171 & 3258 \\
\hline Harwell & WL & 770 & 520 & 98 & 211 & 582 & 1289 & 2060 & 1833 & 1270 & 276 & 524 & 1332 & 3282 & 49 & 827 & 549 & 131 & 230 & 553 & 1470 & 2400 \\
\hline Mace Head & $\mathrm{HD}$ & 257 & 107 & 15 & 30 & 105 & 437 & 8 & 632 & 289 & 57 & 95 & 241 & 1193 & 26 & & 167 & 37 & 0 & 142 & 625 & 1343 \\
\hline Finokalia & FKL & 316 & 211 & 55 & 90 & 220 & 498 & 918 & 1624 & 1210 & 275 & 542 & 1345 & 2707 & & 949 & 691 & 150 & 288 & 779 & 1600 & 2368 \\
\hline JRC-Ispra & ISP & 1617 & 1302 & 476 & 734 & 1341 & 2386 & 3714 & 5571 & 4165 & 1040 & 2032 & 4448 & 9334 & 13918 & 2888 & 1943 & 363 & 829 & 2129 & 4953 & 8317 \\
\hline Zeppelin & ZEP & 8 & 9 & 1 & 2 & 8 & 5 & & & 53 & 3 & 17 & 68 & 213 & & 61 & 27 & 1 & 8 & 37 & 122 & 202 \\
\hline & PDD & 402 & 279 & 7 & 12 & 291 & & & & 671 & & & & 2238 & & & & & & & & 1821 \\
\hline & SSL & & 40 & 127 & 200 & 41 & & 13 & 1436 & 1060 & 220 & 4 & 1242 & 24 & & & & 0 & 23 & 6 & 1342 & 1887 \\
\hline & ZSF & 269 & 183 & 42 & 79 & 19 & 44 & & 77 & 43 & 6 & 13 & 47 & 1532 & 228 & & 22 & 26 & 60 & 241 & 945 & 1470 \\
\hline & JFJ & & 76 & 2 & 3 & 79 & 16 & 30 & & 18 & 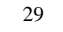 & 69 & 19 & 57 & 10 & 16 & 81 & 0 & 26 & 87 & 321 & 606 \\
\hline BEO & & 27 & 145 & 35 & 56 & 13 & 41 & 93 & 1072 & 54 & 5 & 14 & 70 & 20 & 32 & 64 & 29 & 2 & 63 & 399 & 1338 & 1933 \\
\hline Monte Cimone & CMN & 343 & 206 & 48 & 92 & 204 & 486 & 1104 & 890 & 503 & 48 & 142 & 667 & 1643 & 2519 & 504 & 238 & 11 & 51 & 356 & 987 & 1440 \\
\hline
\end{tabular}

surements were stored in EMEP data flags in the meta data stored together with the dataset. For the results provided in this paper, only EUSAAR level II data marked as a "Valid measurement" were used. The data are provided in the database as one-hour geometric or arithmetic mean values, with EUSAAR current recommendation being arithmetic average. Before analysing the data for this article, the we tested the averaging methods using high time resolution data from stations SMR and JFJ. The differences in time-averaging did not have a substantial effect on any of the concentrations used in this paper (not shown). The geometric mean value calculations had a limit for the low value of concentration, which is set to $10^{-6}$ particles per cubic centimetre. This value could have an effect on the geometric mean values of periods with extremely low concentrations of particles.

Before analysis, the files were analysed to ensure that the time-vectors and the concentration data were of the right format and comparable with each other. For stations with multiple size resolutions over the analysis period, the size distribution functions were interpolated to uniform size intervals. This interpolation had no effect on the integrated concentrations. Station specific night-time filters were calculated using a sunrise/sunset algorithm, defining daytime as time when any part of the sun was above the visible horizon (DuffettSmith, 1988). For the geometric mean and standard deviation calculation, a filter was used to remove zero concentrations from the data and replace them with a concentration $10^{-6} \mathrm{~cm}^{-3}$.

\section{Results}

\subsection{Data coverage}

The overall seasonal coverage (Fig. 3) was adequate for determining main features of the concentrations. The data coverages for both years are also tabulated in Table 5. Although the data coverage was generally good, the coverage was at some stations fragmentary.

\subsection{Seasonality and variability of size distributions}

As discussed earlier, the use of only median or mean values are not necessarily representative of the concentrations and size distributions observed. We present number size distributions in seasonally calculated percentiles of the size-specific concentrations. Figures 4, 5, 6 and 7 show the number size distribution variation of Nordic and Baltic stations, Central European stations, high altitude (or mountain) stations and other stations respectively. The Figures show the median, 16th and 84-th percentile of each measured size section. The shaded areas between 16-th and 84-th percentiles are indicative of each size interval $d n / d \log _{10} d_{p}$ histogram shape. To guide the eye on the scales, plots have a horizontal dotted line indicating $d n / d \log _{10} d_{p}$ of $1000 \mathrm{~cm}^{-3}$. Additionally, we fitted log-normal mode or modes to the median size distributions. These fitted parameters are discussed in Appendix A.

The aerosols at the Nordic stations in Fig. 4 show several similarities. The number size distributions of particles are greater in summer than in other seasons, especially for the Aitken mode particles with dry diameters from 50 to $100 \mathrm{~nm}$. This elevated number size distributions are accompanied by 
Table 5. Data coverage and standard deviations $\left(\sigma(n)\right.$, in $\left.\mathrm{cm}^{-3}\right)$, geometric standard deviations $\left(\sigma_{g}(n)\right.$, unitless $)$ and 1-h autocorrelation rates (A1, unitless) of concentrations.

\begin{tabular}{|c|c|c|c|c|c|c|c|c|c|c|c|c|}
\hline \multirow[b]{2}{*}{ Stat. } & \multicolumn{3}{|c|}{ Data Coverage (\%) } & \multicolumn{3}{|c|}{$N_{30-50}$} & \multicolumn{3}{|c|}{$N_{50}$} & \multicolumn{3}{|c|}{$N_{100}$} \\
\hline & Total & 2008 & 2009 & $\sigma(n)$ & $\sigma_{g}(n)$ & $\mathrm{A} 1(\mathrm{n})$ & $\sigma(n)$ & $\sigma_{g}(n)$ & $\mathrm{A} 1(\mathrm{n})$ & $\sigma(n)$ & $\sigma_{g}(n)$ & $\mathrm{A} 1(\mathrm{n})$ \\
\hline ASP & 77 & 61 & 93 & 307 & 2.25 & 0.85 & 747 & 2.09 & 0.95 & 383 & 2.21 & 0.97 \\
\hline BIR & 47 & 51 & 43 & 209 & 2.62 & 0.91 & 575 & 2.73 & 0.96 & 288 & 2.68 & 0.97 \\
\hline PAL & 80 & 73 & 87 & 229 & 3.41 & 0.91 & 404 & 3.7 & 0.97 & 232 & 6.02 & 0.97 \\
\hline PLA & 23 & 0 & 46 & 666 & 2.4 & 0.91 & 2202 & 2.2 & 0.94 & 1385 & 2.31 & 0.94 \\
\hline SMR & 98 & 99 & 97 & 315 & 2.57 & 0.89 & 686 & 2.28 & 0.95 & 324 & 2.26 & 0.96 \\
\hline VHL & 80 & 80 & 79 & 377 & 2.21 & 0.91 & 888 & 1.97 & 0.95 & 397 & 2.04 & 0.96 \\
\hline BOS & 53 & 18 & 87 & 724 & 1.76 & 0.84 & 1615 & 1.93 & 0.94 & 865 & 2.07 & 0.95 \\
\hline KPO & 55 & 45 & 64 & 761 & 2.67 & 0.87 & 2032 & 2.0 & 0.95 & 1101 & 2.01 & 0.95 \\
\hline OBK & 75 & 64 & 87 & 702 & 2.67 & 0.88 & 1713 & 2.11 & 0.93 & 1018 & 2.1 & 0.94 \\
\hline HPB & 59 & 20 & 98 & 298 & 1.79 & 0.9 & 781 & 2.01 & 0.94 & 467 & 2.28 & 0.95 \\
\hline MPZ & 89 & 92 & 86 & 967 & 2.48 & 0.82 & 1517 & 1.92 & 0.94 & 854 & 1.99 & 0.96 \\
\hline WAL & 50 & 4 & 97 & 774 & 2.02 & 0.89 & 1510 & 1.9 & 0.96 & 752 & 1.94 & 0.97 \\
\hline CBW & 57 & 57 & 58 & 1238 & 2.21 & 0.86 & 2225 & 2.31 & 0.92 & 931 & 2.5 & 0.95 \\
\hline HWL & 64 & 74 & 54 & 581 & 2.44 & 0.91 & 1406 & 2.4 & 0.96 & 685 & 2.44 & 0.96 \\
\hline MHD & 66 & 66 & 67 & 272 & 3.41 & 0.93 & 784 & 3.14 & 0.96 & 396 & 2.89 & 0.96 \\
\hline FKL & 27 & 17 & 37 & 259 & 2.31 & 0.92 & 1064 & 2.2 & 0.95 & 654 & 2.28 & 0.96 \\
\hline ISP & 81 & 92 & 71 & 985 & 1.82 & 0.83 & 3868 & 2.17 & 0.94 & 2392 & 2.51 & 0.96 \\
\hline ZEP & 77 & 78 & 77 & 141 & 5.33 & 0.91 & 133 & 4.66 & 0.93 & 61 & 5.4 & 0.98 \\
\hline PDD & 57 & 81 & 33 & 309 & 2.23 & 0.87 & 968 & 3.17 & 0.95 & 552 & 4.18 & 0.95 \\
\hline SSL & 88 & 93 & 83 & 379 & 2.02 & 0.9 & 933 & 2.29 & 0.95 & 535 & 2.5 & 0.96 \\
\hline ZSF & 61 & 24 & 98 & 206 & 2.36 & 0.91 & 699 & 3.12 & 0.97 & 450 & 3.68 & 0.97 \\
\hline $\mathrm{JFJ}$ & 76 & 75 & 78 & 89 & 2.25 & 0.9 & 293 & 2.93 & 0.95 & 180 & 3.67 & 0.95 \\
\hline BEO & 43 & 0 & 87 & 306 & 2.69 & 0.86 & 989 & 3.72 & 0.95 & 620 & 4.43 & 0.96 \\
\hline $\mathrm{CMN}$ & 60 & 51 & 68 & 341 & 2.43 & 0.88 & 749 & 3.39 & 0.95 & 450 & 4.54 & 0.95 \\
\hline
\end{tabular}

a slightly larger diameter of median diameter of the Aitken mode. The number size distributions were consistently lower in winter at all Nordic stations. The influence of nucleation for the smallest particles is not clearly visible on the 84th percentile size distributions, although some elevated number concentrations of sub- $20 \mathrm{~nm}$ particles are visible at the SMR and PAL stations in spring and autumn. All of the stations show a bimodal median number size distributions. The more northern PAL station size distributions had similar seasonality, but number size distribution level was about half that of the other Nordic stations with more pronounced summer effect than at ASP, SMR or VHL. The Nordic station size distributions are well in agreement with earlier studies (Tunved et al., 2003; Dal Maso et al., 2008).

The Baltic PLA station has different aerosol distribution shapes than Nordic stations. The spring and summer number size distributions shapes were close to those observed at ASP and VHL, but with with a wider, almost unimodal, distribution shape. The winter and autumn concentrations had larger median diameters, but much lower Aitken mode concentrations.

The Central European stations in Fig. 5 show generally greater concentrations than at the Nordic stations. All Central European stations have very similar size distributions regardless of the season, although KPO had elevated concen- trations in accumulation mode in winter and autumn. The concentrations of sub- $30 \mathrm{~nm}$ particles are elevated at HPB in spring and MPZ and OBK in summer, suggesting contribution of nucleated particles to the size spectrum. All sites, except HPB - which is close to being a high-altitude site $(988 \mathrm{~m})$ - show remarkably similar median number size spectra and concentrations suggesting a relatively stable number size distribution over the central European plain from Germany to Hungary.

At high-altitude sites (defined as height over $1000 \mathrm{~m}$ above mean sea level), aerosol number size distributions are similar, even though there are large spatial distances between the stations (Fig. 6). The number concentrations were low compared to nearby lowland sites. The number size distributions generally show bimodal behaviour, although the modes are overlapping at some of the stations. The seasonal cycle is similar at all sites, with greater concentrations during summer, especially for particles over $70 \mathrm{~nm}$ in diameter. The intra-seasonal variability is considerable especially in summertime, suggesting a range of different types of airmasses most likely boundary layer air during daytime and clear tropospheric air during nighttime (see e.g. Venzac et al., 2009; Weingartner et al., 1999). 


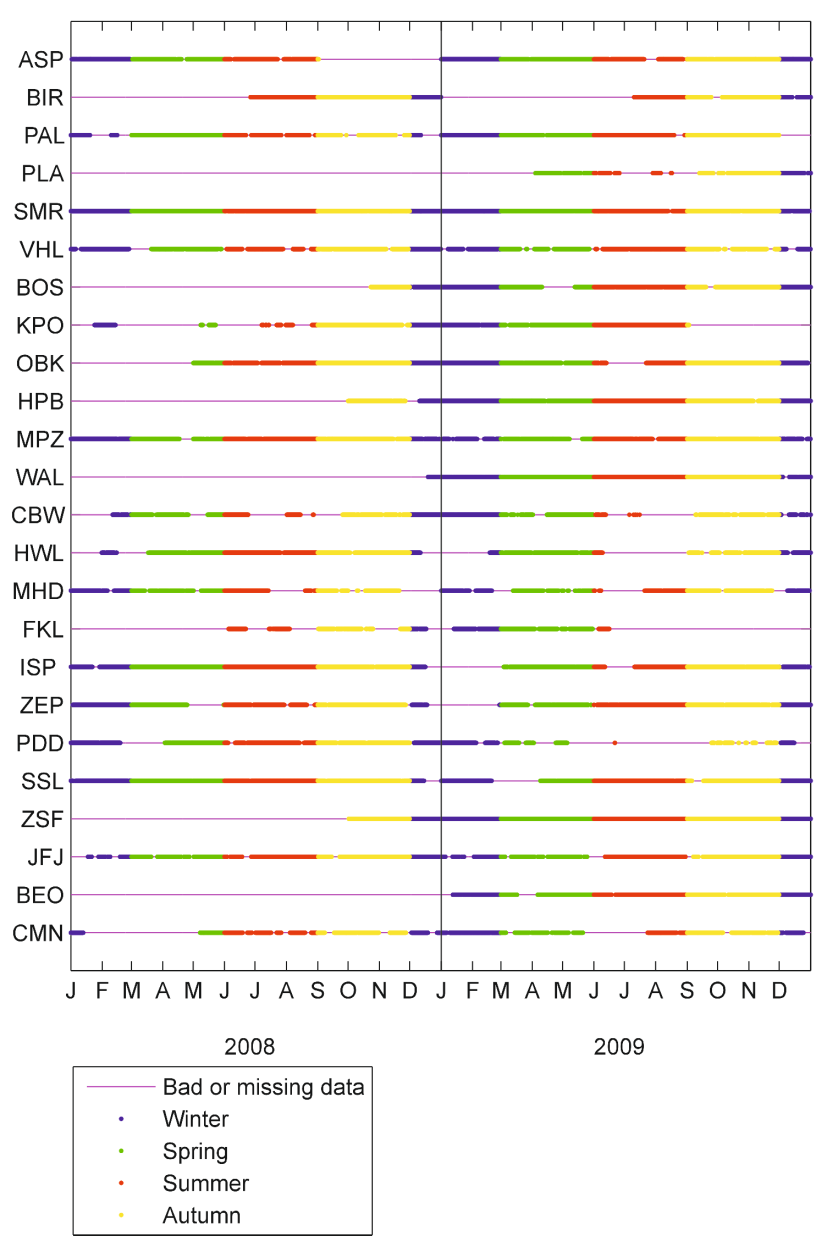

Fig. 3. Data coverage of the stations. Colours indicate the valid data per season. Notable is that all, except one (spring at BIR), of the stations had at least some coverage in all seasons, and most of the stations were operating in both years 2008 and 2009.

The Western European stations (Fig. 7 top row) show more inter-station variability. Station CBW size distributions have similar behaviour as Central European stations, with high concentrations and almost unimodal size distribution and small differences between seasons. The HWL and MHD stations have high seasonal variation and large variance of intra-seasonal concentrations. The HWL station data show a prominent spring-summer maximum in all sizes from 30 to $70 \mathrm{~nm}$. Winter and autumn distributions lack this maximum in the smallest size ranges. During the summer months, MHD presents relatively large variation with number size distribution maxima in the 30 to $50 \mathrm{~nm}$ diameter - with the rest of the seasons having much lower concentrations. The variability was probably due to occurrences of both clean Atlantic and polluted local airmasses and the maximum value at MHD during summer months can be attributed to enchanted marine biota activity which increases the sub-micron parti- cle concentration of non-seasalt sulphate and organic aerosol (Yoon et al., 2007).

At the Mediterranean station FKL, the aerosol number size distributions were bimodal for winter with an Aitken mode around $50 \mathrm{~nm}$ and accumulation mode $150 \mathrm{~nm}$. The spring and summer were dominated by strong accumulation mode at around $100 \mathrm{~nm}$. At ISP station in Northern Italy (Fig. 7) the concentrations were much greater. The ISP number concentrations were comparable with most polluted Central European station number concentrations in summer and autumn. The winter and autumn median distributions show extremely high number concentrations of accumulation mode particles around $100 \mathrm{~nm}$.

The only Arctic station, ZEP, has a very distinctive seasonal cycle (Fig. 7). During winter and autumn, the aerosol concentrations were very low with their maxima at around $200 \mathrm{~nm}$. The springtime distributions are dominated by Arctic haze, strongly increasing the concentrations in accumulation mode. In summertime, the distribution changes to very clean marine bimodal distribution, with a strong Aitken mode around $30 \mathrm{~nm}$. This seasonal change is connected to different meteorological situations, daylight as well as changes in ocean ice cover. Concentrations at ZEP were very low compared to European mainland concentrations.

\subsection{Particle number concentrations in different size ranges}

Number concentrations in different size ranges $\left(N_{30-50}, N_{50}\right.$ and $\left.N_{100}\right)$ of the stations are presented as histograms of the number concentrations plotted with logarithmically even size intervals of 20 sections per decade (Fig. 8). All of the histograms are normalized by the total number of valid measurements, and the sum of the seasonally separated histograms (lines in colour) is equal to the total number concentration histogram (in black). The annual concentration histogram of the night-time values (determined as described in Sect. 2.2.3) is shown as shaded area. The part of the total number concentration histogram above the shaded area is the part of the concentrations coming from the day-time measurements. Figures 9,10 and 11 show the histograms of the $N_{30-50}, N_{50}$ and $N_{100}$ concentrations.

The stations in Northern Europe are especially sensitive to a selection bias of day-night difference, as the length of day is highly variable between the seasons. Stations PAL and ZEP have parts of the year completely in night-time and part completely in day-time, causing the summer and winter to be overly represented in night-time and day-time histograms. The percentiles of the concentrations are also tabulated with respective mean values in Table 4. 

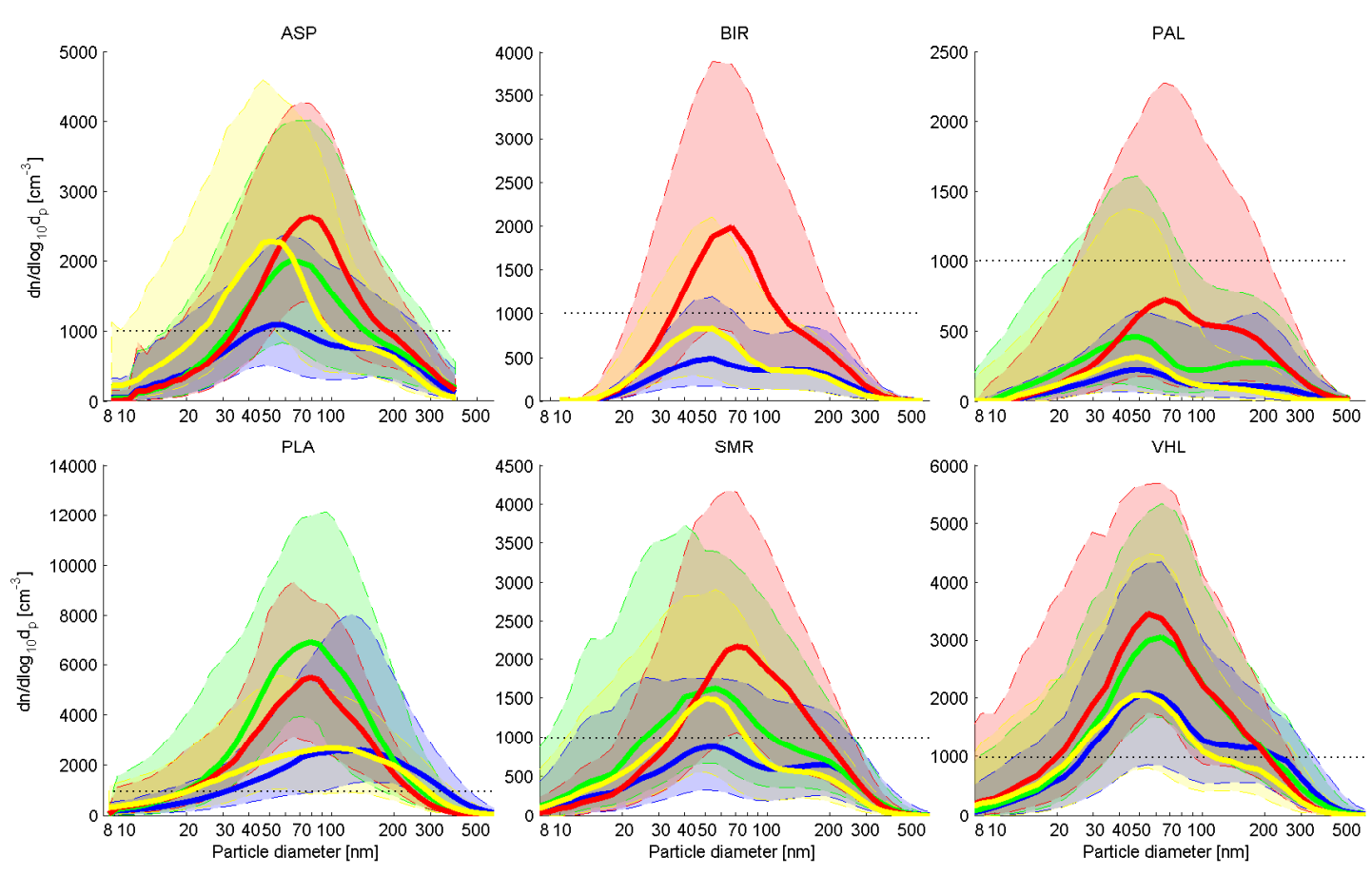

Fig. 4. Median distributions (solid line) and 16th and 84th percentile distributions (shaded areas) divided by seasons at Nordic and Baltic (PLA) stations. The black dotted line shows the 1000 particles $\mathrm{cm}^{-3} d n / d \log _{10} d_{p}$ to help the eye on the concentration levels. Blue line and shading denote winter, green line and shading spring, red line and shading summer and yellow line and shading autumn months datasets.
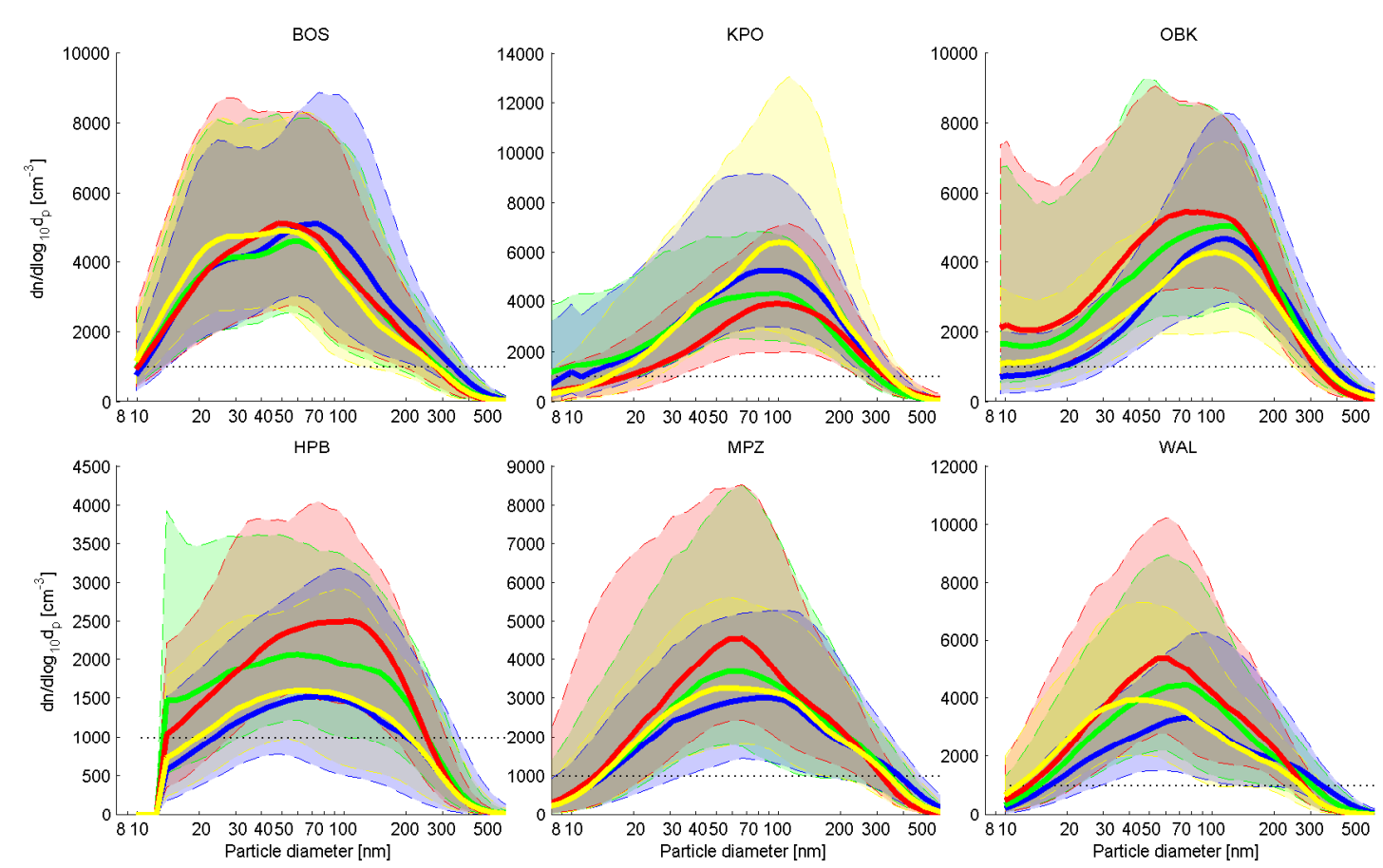

Fig. 5. Median distributions (solid line) and 16th and 84th percentile distributions (shaded areas) divided by seasons at Central European stations. Notation as in Fig. 5. 

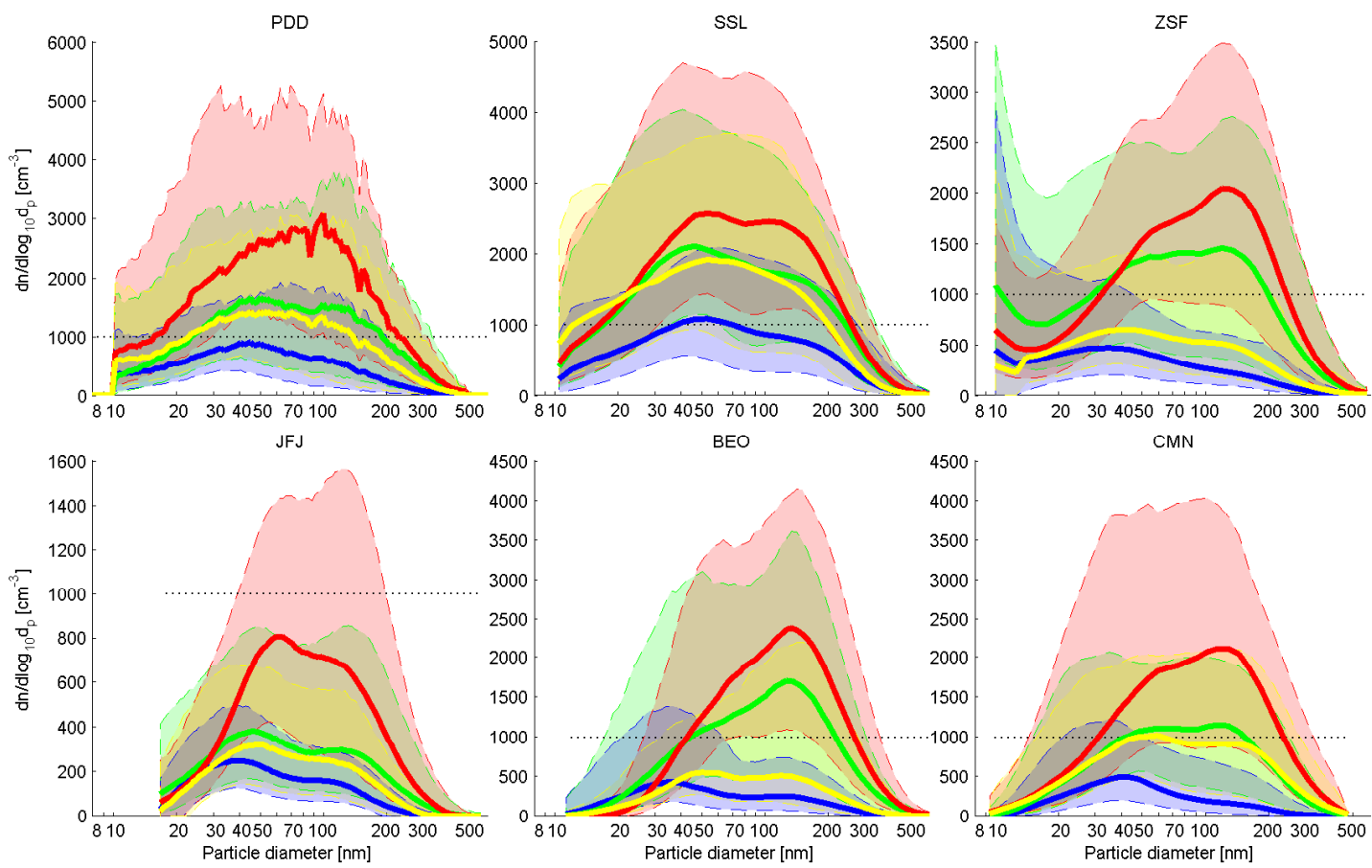

Fig. 6. Median distributions (solid line) and 16th and 84th percentile distributions (shaded areas) divided by seasons at high altitude stations. Notation as in Fig. 4.
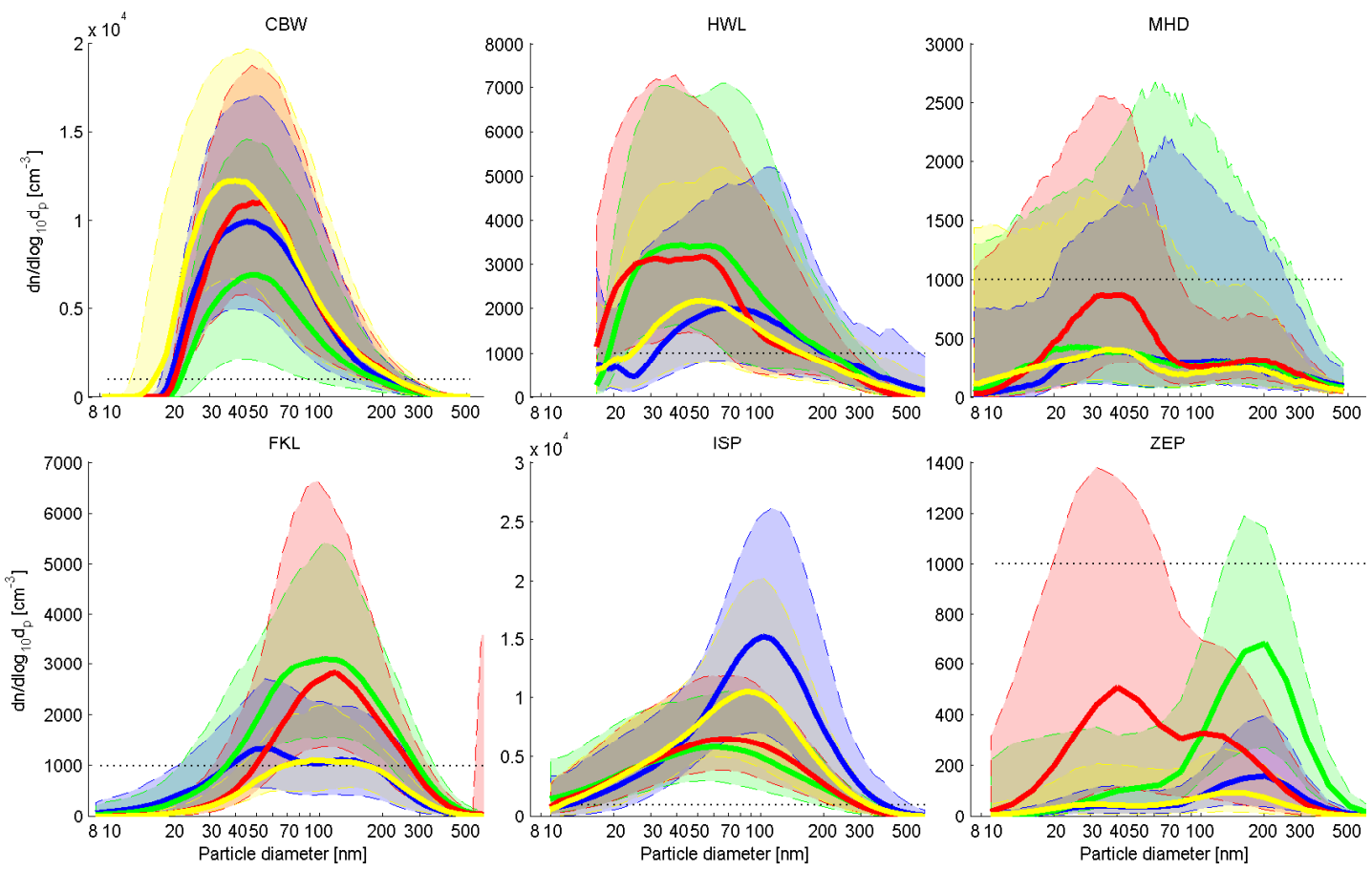

Fig. 7. Median distributions (solid line) and 16th and 84th percentile distributions (shaded areas) divided by seasons at West European, Arctic and Mediterranean stations. Notation as in Fig. 4 . 

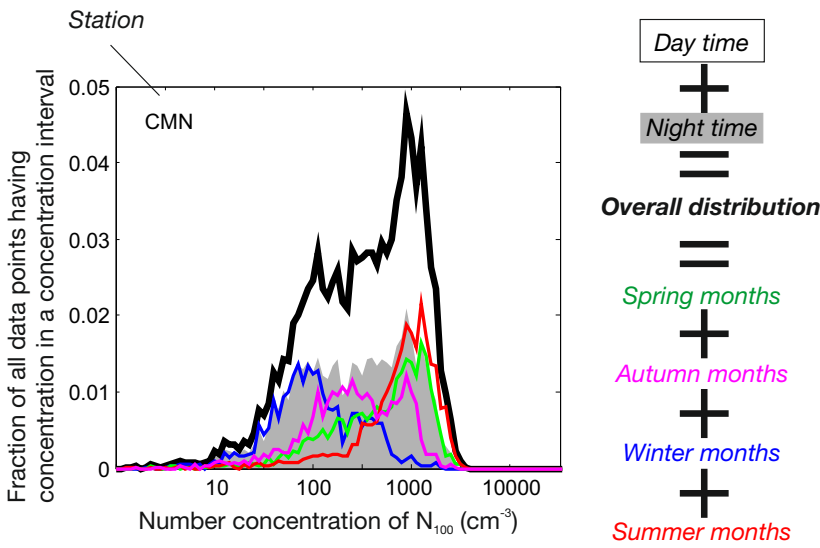

Fig. 8. Example of the number concentration histograms used in Figs. 9-11. The black line shows the histogram (with equal log distributed bins) of all available data from the station. The seasonal histograms are normalized to total amount of available data; they sum up to the total histogram value. The shaded area shows the similarly normalized histogram of only night-time samples. The white area above is the fraction of the total histogram which was from the day-time samples.

\subsection{1 $N_{30-50}$ concentrations}

The histograms of Nordic and Baltic $N_{30-50}$ concentrations are presented in Figs. 9a-f. The Nordic stations ASP, BIR, SMR and VHL all show similar overall number concentration histograms in this size class, with a fairly log-normal shape and somewhat lower wintertime concentrations. The seasonality (change of position or shape of the coloured lines) is relatively low at the SMR and VHL stations in this concentration range. The day-night cycle did not seem to have a strong influence to number concentrations in these stations, indicating low sensitivity in respect to diurnal cycles. The more northern PAL station had some similarities with the rest of the Nordic stations, but the concentrations seem to be more variable (i.e. histogram is wider) and the effect of seasonal changes in day-time length is visible in the differences between the night-time histogram and the total histogram. The overall median $N_{30-50}$ of the Baltic PLA station was also in the same range as most of the Nordic stations as was the shape of the overall annual histogram.

The Central European stations have all a very similar narrow log-normal shape of the $N_{30-50}$ histogram with very low seasonal variation (Fig. $9 g-1$ ). The greatest concentrations were somewhat increased during day-time at MPZ, OBK and HPB, but otherwise no clear day/night variation can be seen. The median $N_{30-50}$ concentrations varied from $410 \mathrm{~cm}^{-3}$ in HPB to $1120 \mathrm{~cm}^{-3}$ in BOS.

Of the western European stations, the CBW station (Fig. 9m) has an unimodal $N_{30-50}$ histogram with low seasonal variation, similar to Central European stations. CBW $N_{30-50}$ concentrations were high, with a median of $1914 \mathrm{~cm}^{-3}$. The HWL and MHD stations' histograms (Fig. 9n and o) show seasonal variation with greatest concentrations during spring time in HWL, and summertime in MHD. Both stations have a very widely spread histogram in all seasons suggesting high variability in concentrations. HWL $N_{30-50}$ concentration median was $580 \mathrm{~cm}^{-3}$. MHD had in general low $N_{30-50}$ concentrations, with an annual $N_{30-50}$ median at $100 \mathrm{~cm}^{-3}$.

The FKL station in Greece had greatest $N_{30-50}$ concentrations during spring and winter with no apparent day/night difference. The concentration levels were relatively low, with a median concentration of $220 \mathrm{~cm}^{-3}$. ISP histogram has similar behaviour with the Central European ones with unimodal log-normal shape and low seasonality, but with high concentrations of $1340 \mathrm{~cm}^{-3}$.

ZEP station in Svalbard Islands (Fig. 9r), had a unique and strong $N_{30-50}$ seasonal cycle, with greater summer $N_{30-50}$ concentrations of around 100 particles $\mathrm{cm}^{-3}$, compared to $N_{30-50}$ concentrations of around $10 \mathrm{~cm}^{-3}$ in other seasons. Some extreme concentrations were also observed in the wintertime. The day/night cycle at the ZEP station is very strongly connected to the seasonal cycle, with almost all observations larger than $100 \mathrm{~cm}^{-3} N_{30-50}$ occurring during summer when the sun was above the horizon.

All of the $N_{30-50}$ histograms at mountain sites (Fig. 9s-x) have similarities, with almost log-normal shapes, with clear concentration tails towards greater concentrations, and similar seasonal cycles. The winter conditions, probably more representative of the free troposphere, were characterized by lower concentrations. The summertime histograms show greatest concentrations, probably due the planetary boundary layer and/or valley winds influence. The greatest concentrations were generally observed during day-time, especially at stations BEO, PDD and CMN. The median concentrations varied between $79 \mathrm{~cm}^{-3}$ for JFJ and $418 \mathrm{~cm}^{-3}$ for SSL.

\subsubsection{CCN-sized aerosol number concentrations}

The distributions of $N_{50}$ and $N_{100}$ concentrations are shown in Figs. 10 and 11.

The $\mathrm{CCN}$-sized aerosol number concentration histograms of the Nordic stations are similar for both $N_{50}$ and $N_{100}$ (Figs. 10a-c, e-f and 11a-c, e-f). The stations in general had greater concentrations in summertime, although the concentrations at ASP and PAL were also elevated during spring. The BIR station had bimodal summer histograms with a lower $N_{50}$ concentration mode around 700 particles $\mathrm{cm}^{-3}$. The diurnal cycle was not strongly visible in Nordic stations histograms, except for the PAL station, where the diurnal variation was strongly affected by the seasonal variation. PAL station concentrations have a very wide histogram, especially in wintertime, suggesting a wide range of sources affecting the concentrations observed at the station. The greatest $N_{50}$ and $N_{100}$ concentrations observed at the PAL station 
A. Asmi et al.: Submicron particles in Europe 2008-2009

5519
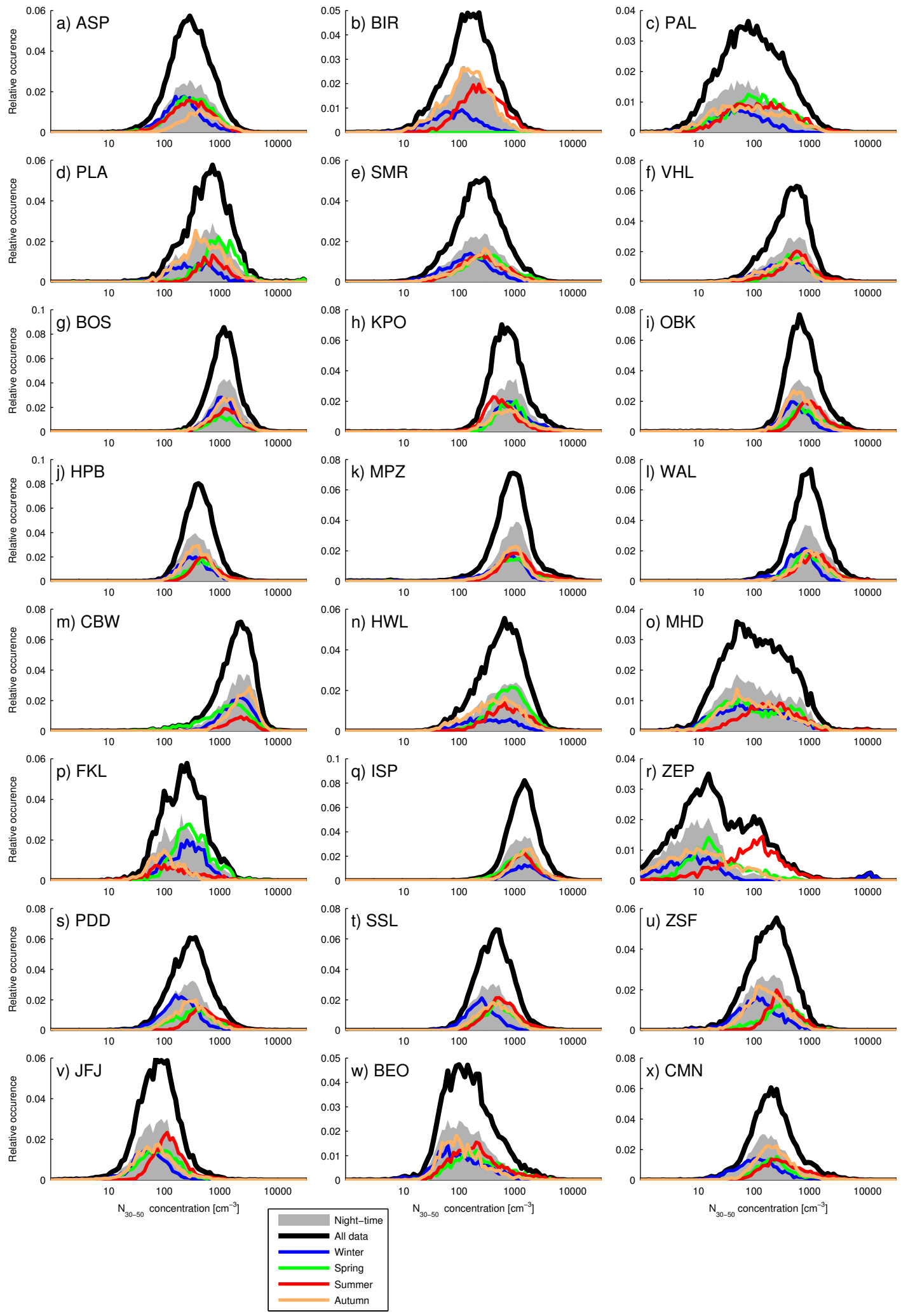

Fig. 9. Histograms of $N_{30-50}$ concentrations at the stations. The concentration bins are evenly distributed in the concentration axes (20 bins/decade) and the y-axes of the figures show the fraction of the values in each bin compared to total number of valid measurements.

www.atmos-chem-phys.net/11/5505/2011/

Atmos. Chem. Phys., 11, 5505-5538, 2011 

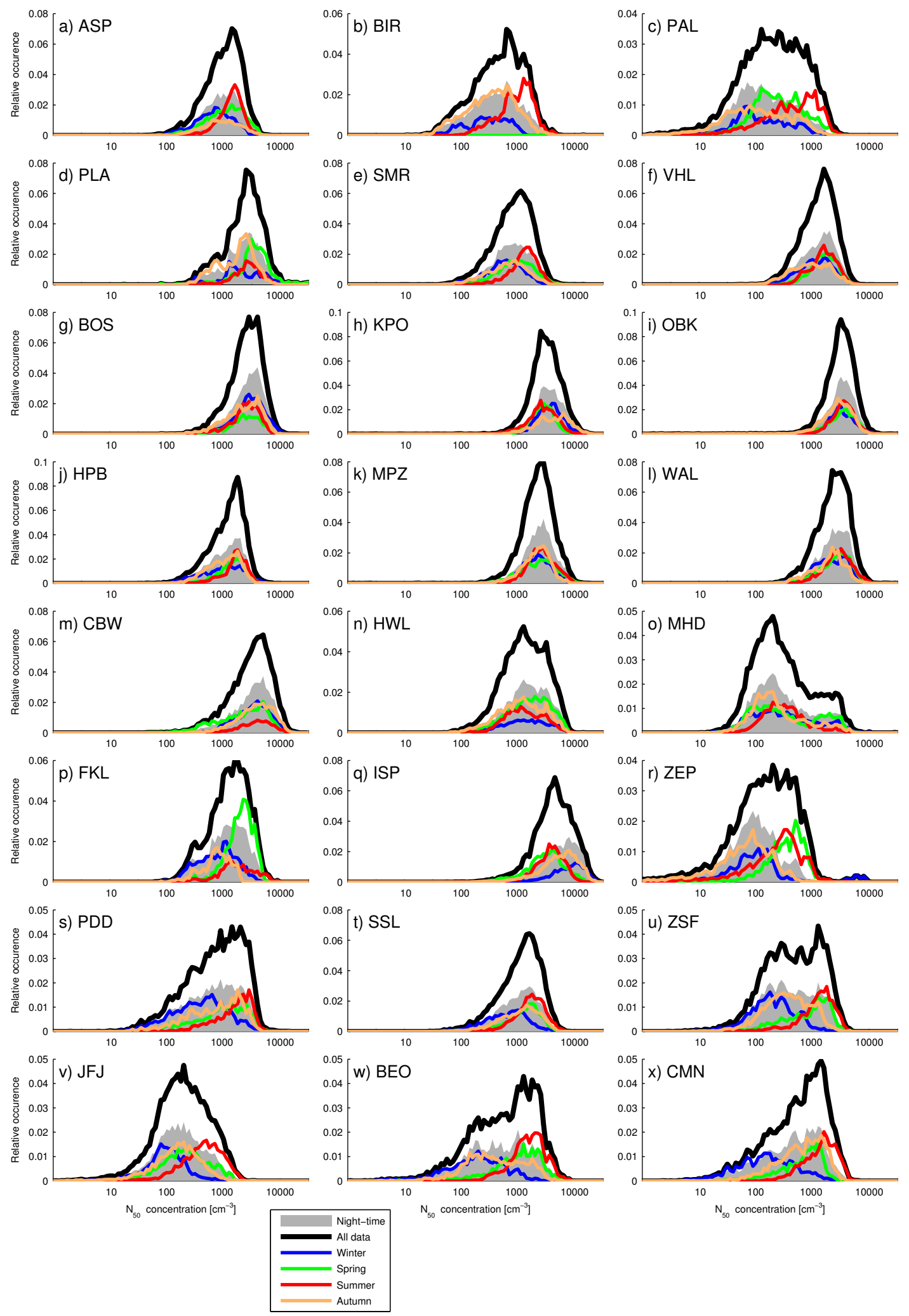

Fig. 10. Histograms of $N_{50}$ concentrations at the stations. See Fig. 9 for nomenclature. 

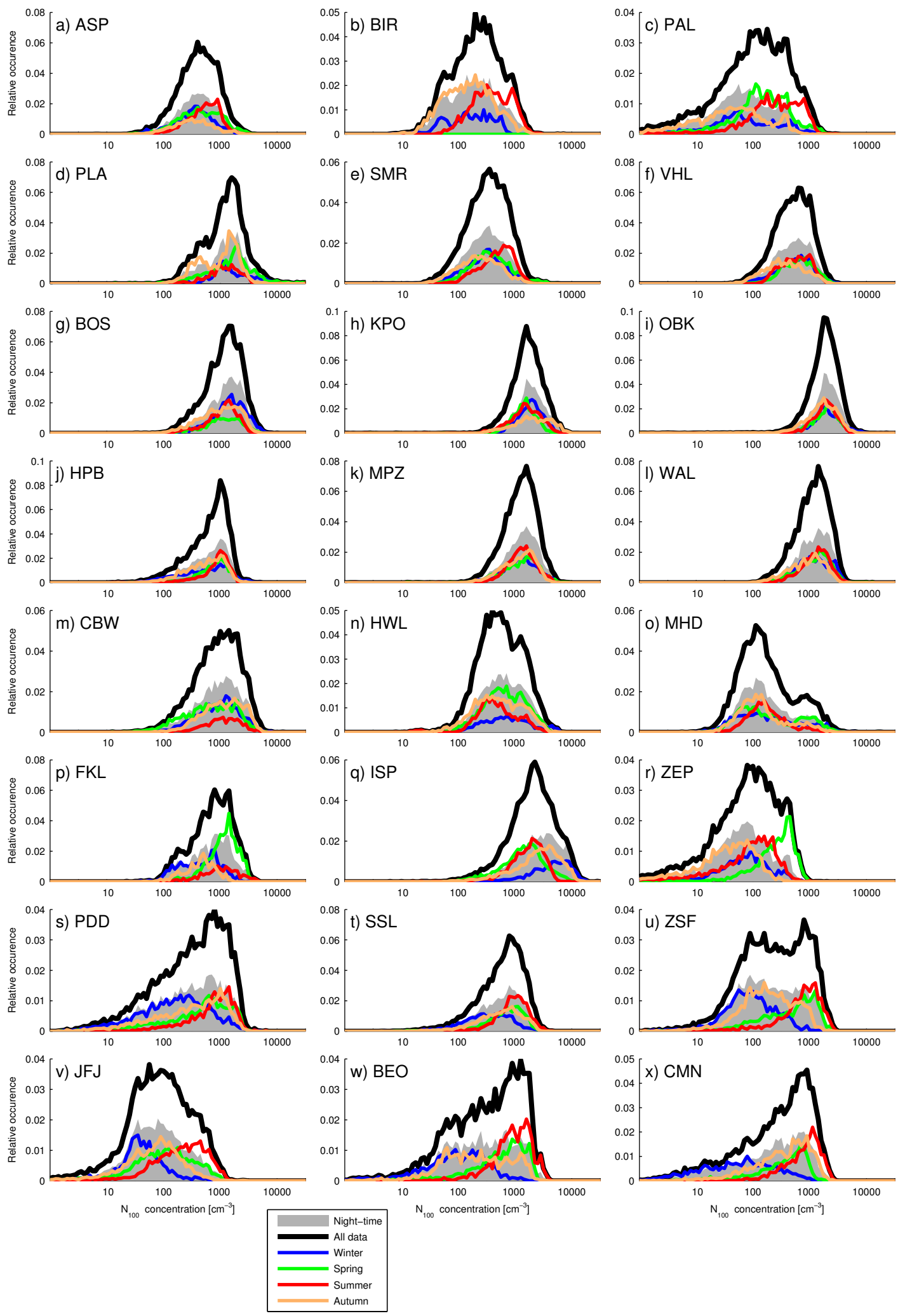

Fig. 11. Histograms of $N_{100}$ concentrations at the stations. See Fig. 9 for nomenclature. 
were observed during the summer. The seasonal variations are large at all Nordic stations, except at VHL.

The Baltic PLA station (Figs. 10d and 11d) has multimodal histograms during springtime, which shows influence of both cleaner and more polluted airmasses. For other seasons, the PLA station histograms are almost unimodal and similar to the concentration histograms at Central Europe (below).

All Central European sites had similar $\mathrm{CCN}$ concentration histograms (Fig. 10g- 1 and $11 \mathrm{~g}-1$ ). The $N_{50}$ and $N_{100}$ histograms have very similar shapes, and they only differ by the magnitude of concentrations. There is very little seasonal change in the histograms. Most of the greatest concentrations were observed during daytime. The $N_{50}$ and $N_{100}$ concentrations were relatively high at the Central European stations, with median $N_{50}$ concentrations of between 1325 and $3120 \mathrm{~cm}^{-3}$ at HPB and KPO, and $N_{100}$ between 739 and $1863 \mathrm{~cm}^{-3}$ at HPB and OBK.

Western European stations do not have as clear a common behaviour as the Central European stations (Figs. 10m$\mathrm{o}$ and $11 \mathrm{~m}-\mathrm{o}$ ). Station CBW histogram is similar to Central European stations with a unimodal shape, high concentrations especially for $N_{50}$ (median $3387 \mathrm{~cm}^{-3}$ ) and the absence of seasonal variation. The HWL station histograms are, as is the case with $N_{30-50}$ concentrations, widely dispersed over the concentration axis with a two-modal histogram suggesting influence of cleaner and more polluted airmasses. These results agree with earlier cluster analysis results, where the clean Atlantic and polluted Londonarea/continental airmasses were easily distinguishable from HWL observations (Charron et al., 2008). The MHD station histogram shared a two-modal histogram with HWL. Most of the MHD $N_{100}$ histogram is located at low concentrations with approximately 200 particles $\mathrm{cm}^{-3}$, but with a second mode at about order on magnitude greater concentrations. This is well in line with previous studies from the MHD station showing the importance of the difference between airmasses arriving over the relatively clean Atlantic ocean contrasted by polluted airmasses arriving from Britain and mainland Europe (McGovern et al., 1996). The CCN concentrations in the mode with greater concentrations were of same magnitude as the more polluted mode of HWL. None of the Western European stations have strong seasonal signals in $N_{50}$ or $N_{100}$ concentrations.

Mediterranean FKL station histograms show peaks in $N_{50}$ and $N_{100}$ concentrations during spring of over 1000 particles $\mathrm{cm}^{-3}$ (Figs. 10p and 11p). Another smaller mode of low concentrations was also visible around 500 particles $\mathrm{cm}^{-3}$ in both $N_{50}$ and $N_{100}$. The ISP station histograms are in general similar to Central Europe in both $N_{50}$ and $N_{100}$ during spring and summer (Figs. 10q and 11q). The seasonal changes of these particles are, however, relatively large and ISP histogram has a strong signal from autumn and especially wintertime $\mathrm{CCN}$ concentrations at over 10000 parti- cles $\mathrm{cm}^{-3}$ in $N_{50}$. These high concentrations happened almost exclusively during night-time.

The ZEP station in the Arctic has complex histograms with high seasonality (Figs. 10r and 11r). The day/night variation was dominated by the seasonal variation of light at the station, with relatively high concentrations of both $N_{50}$ and $N_{100}$ in spring and summer daytime.

The Mountain sites all had wide, almost normal distribution shaped, histograms (Figs. 10s- $\mathrm{x}$ and $11 \mathrm{~s}-\mathrm{x}$ ). The seasonal cycle is clearly visible. The wintertime concentrations are much lower than on other seasons. At most mountain sites the greatest concentrations were observed during daytime summer and autumn. This daytime effect could be connected with air masses arriving from lower altitudes bringing more polluted air from below. The $N_{50}$ and $N_{100}$ concentrations are all strongly skewed towards lower concentrations. The lowest concentration tails of the distributions are probably indicative of concentrations of the free tropospheric air. The concentrations of the stations with highest altitude (JFJ, BEO and ZSF) had a more pronounced clean mode with $N_{100}$ concentrations below $100 \mathrm{~cm}^{-3}$.

\subsubsection{Autocorrelations and variations}

Standard deviations, geometric standard deviations and 1autocorrelations of the main number concentrations were calculated only for valid datapoints without any data padding. The autocorrelation values should be considered only as approximate values - if the dataset had many instrumental failures or other unusable data, the relevance of autocorrelation is degraded. The autocorrelation was calculated as the correlation coefficient between the dataset and dataset shifted with one hour (i.e. $A_{1}(n)=\operatorname{Corr}(n(t), n(t+1 h))$ ). Large values of autocorrelation show that the concentrations are typically changing slowly and smoothly.

The results are presented in Table 5. The standard deviations of $N_{30-50}$ number concentrations were rather large, with least variation observed at stations BOS, ISP and HPB. In general, stations with high seasonality had greatest mean variances. The $N_{50}$ and $N_{100}$ had generally smaller geometric standard deviations than $N_{30-50}$, with exception of PAL station and the mountain stations, where the variability of $N_{100}$ increased compared to $N_{30-50}$ aerosols.

The hour-to-hour autocorrelation for $\mathrm{CCN}$ concentrations was very high and uniform at all stations. Autocorrelations of $N_{30-50}$ concentrations are lower and with some station-tostation variability. The high correlation coefficients suggest that the aerosol concentrations rarely changed significantly over 1-h timescales.

\subsubsection{Weekday variations}

The weekday variations were studied by grouping the daily averages of the $N_{30-50}, N_{50}$ and $N_{100}$ concentrations of each station on for each day of the week, and analysing the 
resulting concentration histograms. The daily averaging was to remove the high autocorrelation of the concentrations and thus providing independent samples for testing. We tested the statistical significance of the difference between these day of the week concentrations to other weekdays distributions utilising a non-parametric Wilkinson rank-sum test using a ranksum function in Matlab (Higgins, 2004; MathWorks, Inc., 2010). The null-hypotheses was that each weekday's concentration distribution (i.e. histogram) was of similar shape and with a similar median as the combined histogram of all other days of the week. Even at the relatively highly polluted, and potentially anthropogenic-influenced Central European stations, the histograms differences could not be considered statistically significant with $p=0.05$. The only exception is station BOS $N_{100}$ concentrations, which showed a statistically significant increase in Wednesday concentrations compared to the rest of the weekdays.

As the rank-sum test above only compares the each weekday median to the median of other weekdays separately, we repeated the test using similar non-parametric KruskalWallis test (function kruskalwallis in Matlab) to compare the medians of all weekday samples. The $\mathrm{p}$ value gained from this test is the probability for the null hypothesis that all samples are drawn from the same population (Kruskal and Wallis, 1957; MathWorks, Inc., 2010). None of the stations did showed any statistically significant differences between weekdays with $p=0.05$ in any concentration tested. To further extend the analysis the test was also repeated by grouping the data only to two groups: one with weekend days (Saturday and Sunday) and one with work week days (Monday, Tuesday, Wednesday, Thursday and Friday). Here, only HPB $N_{30-50}$ concentrations and ZSF $N_{100}$ concentrations were different between groups $(p<0.05)$.

\section{Discussion}

The results shown are relevant to climate and air quality studies in several ways. Even though the earlier comparisons brought important aspects, such as mean concentrations, of European submicron particle distributions (e.g. van Dingenen et al., 2004; Tunved et al., 2003), this study shows the concentrations from comparable regional background stations, using the same general period of time and using comparable instruments and data analysis methods. The results of regional background aerosol number concentrations and variability should be usable in e.g. model-tomeasurement comparisons of regional and potentially global aerosol models.

\subsection{Temporal variation of concentrations}

The aerosol seasonal variation depends on the site of study. For central European sites, seasonal changes do not have a major effect in $\mathrm{CCN}$ concentrations. In comparison, for an extremely seasonal station such as ZEP, comparisons between modelled and measured concentrations should take the seasonality differences into account. Year-to-year variabilities were generally low for the stations with both years of data.

The weekday analysis shows that, for the concentrations studied, only a few stations per test had any statistically significant variation of concentrations between weekdays or work-week and weekend. As the analysis was done for the whole dataset, periods of significant weekly cycles can occur at the stations intermittently and the signal can be overshadowed by the other changes in concentrations. The particle concentrations nearer to sources are known to show a weekly cycle in number concentrations (van Dingenen et al., 2004; Rodriguez et al., 2007), but the relative remoteness of most of the stations and annual averaging could have removed an anthropogenic weekly signal from our analysis. A more comprehensive time-series analysis of these signals using e.g. wavelet analysis could provide more information on these cycles.

\subsection{Station representativeness and categorisation}

The aerosol modelling community often works with models with relatively low spatial resolution, often on a scale of parts of degrees. This low resolution has caused concern for model-measurement comparisons, especially for polluted or otherwise potentially heterogeneous regions. The differences in absolute concentrations shown in this paper can vary within a region, but in general the size distribution shape, histograms of concentrations and seasonal behaviours of the aerosol populations are relatively homogeneous over large geographical areas - even in areas with known anthropogenic aerosol sources. The high autocorrelations support this, indicating low temporal (and thus most probably - spatial) variability near the station for the size ranges in question. The variability is larger for $N_{30-50}$ concentrations, than for other concentrations, possibly explained through the lower lifetime of $N_{30-50}$ particles and thus larger sensitivity to sources and sinks (Tunved et al., 2004).

The question of representativeness is dependent on which kind of representativeness is actually expected by the data user. Different definitions of representativeness were discussed in Henne et al. (2010), who studied the representativeness of $\mathrm{O}_{3}$ measurements at ground-based stations in Europe for comparisons with medium-to-large scale models. They categorized the European stations into 6 groups based on estimated $\mathrm{O}_{3}$ source and deposition patterns around the catchment areas of the stations. Of the 24 stations in this study, 15 stations were also categorised by Henne et al. and the resulting representability classes are shown in Table 2 . The groups they determined most useful for large-scale model comparisons were classes 5 (generally remote), 2 (mostly remote). Class 3 (agglomeration) was considered to be least representative of the area around it. 

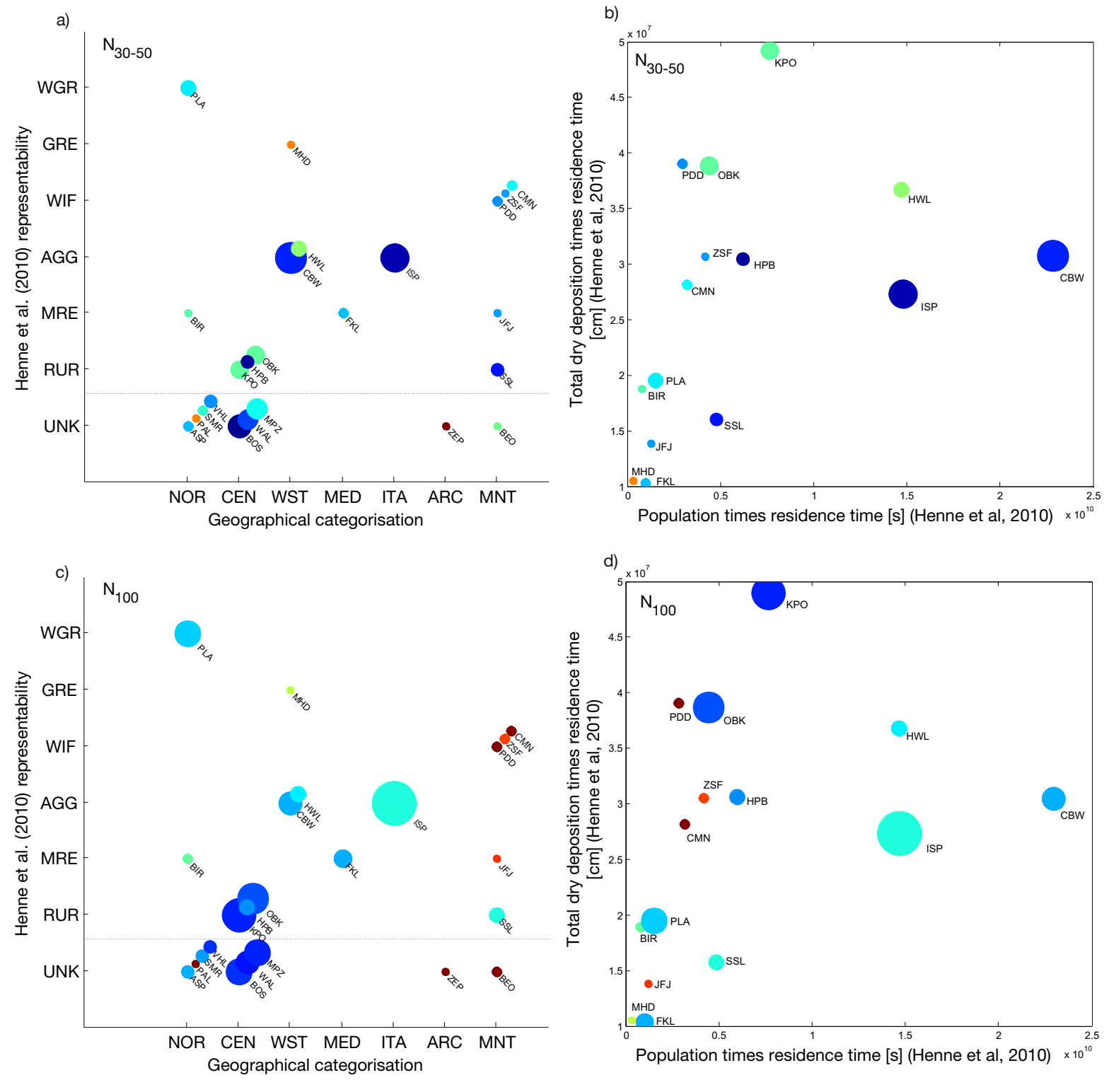

Geometric standard deviation of concentrations
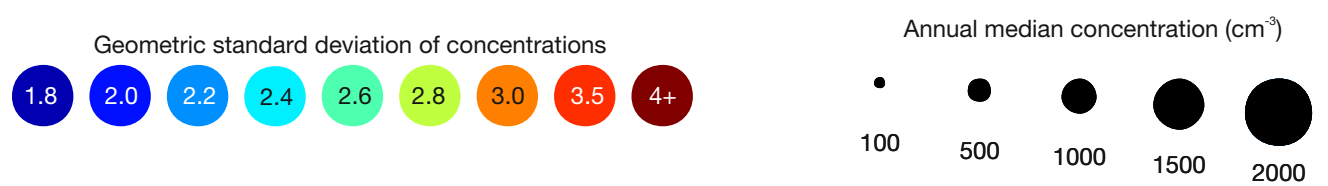

Fig. 12. Station categorisation according to geographical location and Henne et al. (2010) (see text) (a) and (c). The category abbreviations are: WGR - "Weakly influenced, generally remote", GRE - "generally remote", WIF - "weakly influenced", AGG - "agglomeration", MRE - "mostly remote", RUR - "Rural", UNK - unknown, not categorized. The geographical areas are NOR - Nordic and Baltic, CEN - Central Europe, WST - Western Europe, MED - Mediterranean, ITA - North Italy, ARC - Arctic, MNT - Mountains. (a) for $N_{30-50}$ concentrations and (c) for $N_{100}$. On subfigures (b) and (d) are shown the station concentrations and standard deviations as function of Henne et al. (2010) main categorizing parameters, the "catchment area population times residence time" and the "catchment area total $\mathrm{O}_{3}$ deposition times residence time". The values are from $24 \mathrm{~h}$ catchment areas. The colour of the station indicators describe the annual geometric standard deviations of the concentrations in question and the sizes of the indicators show the annual median number concentrations. 
If this categorization would be usable directly for number concentrations of aerosol particles, we would assume that the variability of the aerosol concentrations would be lower in stations categorized as more representative. Especially the concentration histograms should have relatively unimodal shape, as several peaks in histograms are signs of non-homogenous airmasses. Aerosol number concentrations should also follow the main source and sink parameters used in the categorization.

We explore the effectiveness of different categorisations in Fig. 12a and c, which show the stations categorized by geographical and Henne et al. (2010) categories, also showing the annual median concentrations and geometric standard deviations of $N_{30-50}$ and $N_{100}$ concentrations. The geographic categorization seems to capture most of the overall concentration levels quite successfully (i.e. the markers are generally of same size in vertical columns), and the standard deviations of the stations seem to be also reasonably similar. HPB, with relatively high altitude, starts to have lower median concentrations and greatest variability for Central European stations, a common feature with the SSL mountain station. The largest discrepancies are within the Western European group, where CBW is much closer to polluted Central European sites and the differences between HWL and MHD are relatively large.

From the Henne et al. (2010) point of view, the most comparable "Generally remote" classification only had one station, MHD, which based on particle data and multi-peaked histograms does instead show high heterogeneity in particle concentrations. This large variability does not agree with high representability in this sense. The Central European sites are categorized in the "Rural" category which from the ozone point of view was not one of the most representative groupings in Henne et al. (2010) (i.e. one could expect high variability), but from a particle point-of-view show very similar behaviour over a large area with low variability, i.e. potentially high representativeness for the region. Groupings where the Henne et al. (2010) produced relatively similar concentrations and variations were "Weakly influenced" and "mostly remote" which both were considered to be usable for model comparison.

As Henne et al. (2010) classification did not have overall a good agreement with our analysis, we also used the parameters of the classification separately, to find out the reasons for the discrepancies. Fig. $12 \mathrm{~b}$ and d show the stations as a function of two Henne et al. (2010) classification parameters, the 24-h catchment area "population times residence time" (representing the potential immediate sources of pollutants) and the 24-h catchment area " $\mathrm{O}_{3}$ total deposition times the residence time" (representing potential sink terms). The $N_{30-50}$ concentrations increase as the population parameter increases, with some indication of decreasing variability. For $N_{100}$ concentrations, the population parameter has less influence on the concentration levels or on variation. The deposition parameter however does not have such a clear trend on either variability or median concentrations on either concentration studied.

Overall, the Henne et al. (2010) categorization does not seem to agree well with all aerosol measurements. Based on the main parameters used in their categorization, the source term used in their approach do have some similarities with observed aerosol concentrations (i.e. the concentrations were generally greater with bigger source term), but the use of dry deposition parameter as the main sink term does not have good agreement with our results. We recommend caution on using site categorizations derived from non-aerosol pollutants to describe the expected representability of a station in aerosol number concentration point-of-view.

\subsection{Modal concentrations}

The size distribution functions or size range concentrations histograms in Sect. 3 give statistical information on concentrations observed at each station. However, they do not directly inform about the correlation between different particle sizes. We investigate the modal correlations by grouping the data according to geographical regions (see Table 2) and showing the concentrations of particles between 30 and $100 \mathrm{~nm}$ of dry particle diameter (representing Aitken mode) as a function of $N_{100}$ concentrations (representing accumulation mode). The $100 \mathrm{~nm}$ diameter is chosen to present the approximate location of the Hoppel gap (Hoppel and Frick, 1990) between the modes and to be consistent with the $100 \mathrm{~nm}$ cut-off of the $N_{100}$ concentrations. For data visualization purposes, we separated areas with greatest density of observations of each geographical category with contours containing 83 percent of the observations (Fig. 13, see Appendix $\mathrm{C}$ for details on the separation). The shape of the scatter density contour can be interpreted to show the typical relationship between concentrations of the two modes for specific types of stations. If the modal concentrations often change in the same way, the shape of the contour is narrow and symmetrical along diagonal lines of the figure. A narrow, but not a diagonal shape of the contour suggests that the two modes are correlated, but one of the modes has much greater variability in the size distributions observed at the station. If the shape of the contour is circular, the two mode concentrations are not strongly correlated.

The Central European stations concentrations are concentrated in a grouping between 500 and $5000 N_{100} \mathrm{~cm}^{-3}$, with a relationship between the bimodal concentrations (Fig. 13). A similar behaviour can be seen in the low-concentration end of station ISP contour, but with high concentrations of accumulation mode starting to dominate the size distributions at over $2000 \mathrm{~cm}^{-3} N_{100}$ concentrations. The Western European stations are heterogeneous (Fig. 13 yellow contour); Station CBW contributing to the high-concentration end, with similar or even greater, concentrations compared to Central European stations; Station MHD contributing to the narrow low concentration part of the contour below 


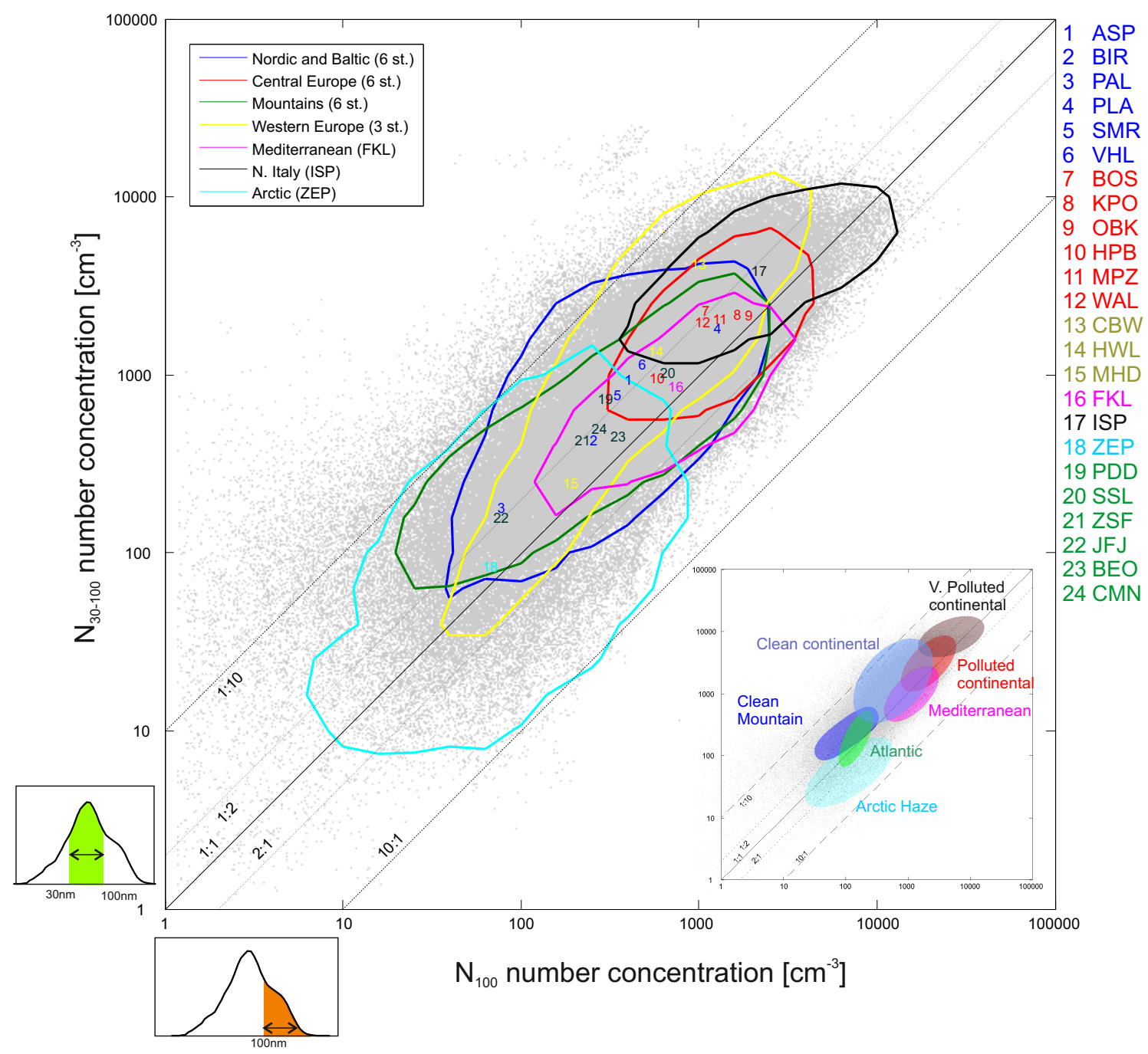

Fig. 13. Scatter plot of particle concentration between 30 and $100 \mathrm{~nm}$ as a function of particle concentrations above $100 \mathrm{~nm}$ (grey points). The station groupings are shown with different colours, with the contours showing the areas with greatest density of each station grouping. The contours are drawn to include $83 \%$ of the each group data points. The colour coded numbers in the plot indicate the coordinates of the geometric means of both concentrations for each station. The insert shows an interpretation of the approximate aerosol types in the same axes. See text for details.

$500 \mathrm{~cm}^{-3} N_{100}$ concentrations and station HWL contributing to the concentrations between these extremes. The mountain stations have a distribution of observations from polluted Central-Europe-type aerosol concentrations to very low accumulation mode and Aitken mode tail. This cleaner end of the mountain station concentrations, with dominant Aitken mode, is likely descriptive of the free tropospheric air observed at the highest mountain stations. Nordic stations form more round shape in middle concentrations, showing greater inter-modal variability and possibly more varied sources of the two modes. Mediterranean FKL station has lower concentrations and slightly more accumulation-mode dominated concentrations than Central European stations. Arctic ZEP station has a unique, very low-concentration contour, where the two modes are widely varying in their concentrations.

Using the interpretations of $N_{100}$ histograms from Sect. 3.3.1, we distinguish phenomenological aerosol types from these Aitken/accumulation mode concentrations (see Fig. 13 insert). The Central European and ISP concentrations show the mode concentration range of the polluted and very polluted European background air. The Mediterranean FKL station contour is considered to be representative of typical Mediterranean regional background, with lower concentrations than Central Europe, but strong correlation between the modes. We interpret the Nordic station contour as representative of clean continental regional background air, with 


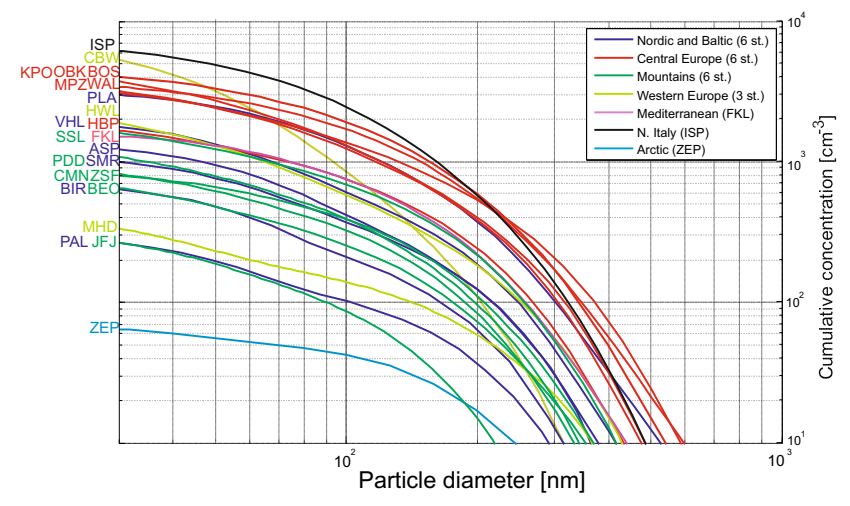

Fig. 14. Cumulative number concentration of the median size distributions at EUSAAR and GUAN stations. The summation was done starting from the largest available size. The plot shows how much particles were above each diameter in the median size distribution interval.

relatively low concentrations and low correlation between the modes.

For the other aerosol types, we use the interpretations from the $N_{100}$ concentration histograms to separate portions of the contours most likely representing specific aerosol types. The low $N_{100}$ concentration end of the mountain station concentrations (below $100 N_{100} \mathrm{~cm}^{-3}$ ) is identified as possible free tropospheric or clean mountain air aerosol, showing dominant Aitken mode concentrations. This hypothesis is supported by removing the relatively low altitude mountain stations (PDD and SSL, both below $2000 \mathrm{~m}$ a.s.1.) from the analysis (not shown), which partially removes the area of the mountain contour which overlaps the Central European contour. The low concentration end of station MHD $N_{100}$ concentrations is interpreted as clean Atlantic marine aerosol. This marine air has low concentrations of accumulation mode particles, but high variability in Aitken mode. The (for the station) high concentrations of $N_{100}$ particles in ZEP station in relation to $N_{30-50}$ and $N_{50}$ particles are interpreted as instances of Arctic haze, identified as the bottom part of the Arctic contour.

\subsection{High activation diameters}

The size ranges used in this article are not necessarily the best choices for all environments. Figure 14 shows the cumulative annual median distributions at the stations, calculated from the largest particle size available towards smaller sizes, showing the median concentration of particles above a certain diameter. In Central European stations, station PLA in Baltic and station ISP in Northern Italy, the median concentration of $N_{100}$ particles are over $1000 \mathrm{~cm}^{-3}$. These are a high, but not unrealistic, amount of particles to be activated as cloud droplets (Martinsson et al., 2000). In these relatively polluted stations, a more useful metric could be derived from larger particle sizes. For this reason, histograms of an additional CCN number concentration $N_{250}$ are shown and discussed in Appendix B.

\subsection{Data usage and access for end-user communities}

We have created usable and relevant statistics from the data. The actual choice of what should be used for the models to compare with, depends on application and complexity needed. The most straightforward way is just to compare one or more mean parameters, such as median concentrations. This approach is simple to do, but can easily lose many features of the data, and, in cases of strongly bimodal histograms, can even be misleading. Comparing modelled histograms to results should pay attention to the histogram mode location (mean or median concentration), width and relative abundance (height) of each mode in the histograms. One method would be to calculate parametric or non-parametric statistical error parameters to compare with modelled and measured distributions.

Although this paper produces a good comparison dataset to compare modelled aerosol concentrations, the ability of a model to correctly produce the measured size distribution or $\mathrm{CCN}$-sized aerosol number distributions in some or all of the stations provided is not enough to ensure the correct distribution of actual CCNs let alone CDNCs. Getting the correct size distribution is a critical first step in this process, but only the first step. There are several complications before a model can be considered to have a realistic representation of CCNs, such as limited horizontal spatial coverage of the measurements, surface measurements instead of cloud-base aerosol concentrations, implicit assumption that aerosol concentration histograms are independent of the cloud formation probability, particle composition, size and surface effects and actual cloud processes dominating the relative humidities leading to droplet activation. These kinds of complex processes need to be taken into account before realistic cloud activation and thus realistic aerosol climate effects in the models can be achieved.

The datasets used in this paper are available directly as time-series from NILU EBAS databank at address http:// ebas.nilu.no/. The data presented in this article (histograms, seasonal profiles, etc) are also stored on a publicly available server at http://www.atm.helsinki.fi/eusaar/. More information on data formats and suggestions on data usage is in Appendix C.

\section{Conclusions}

This study shows the importance of standardized long-term measurements to provide reliable information on statistical behaviour of atmospheric aerosols. Although study encompasses a period of only two years, the data already provides a previously unavailable variety of information on the sub- 


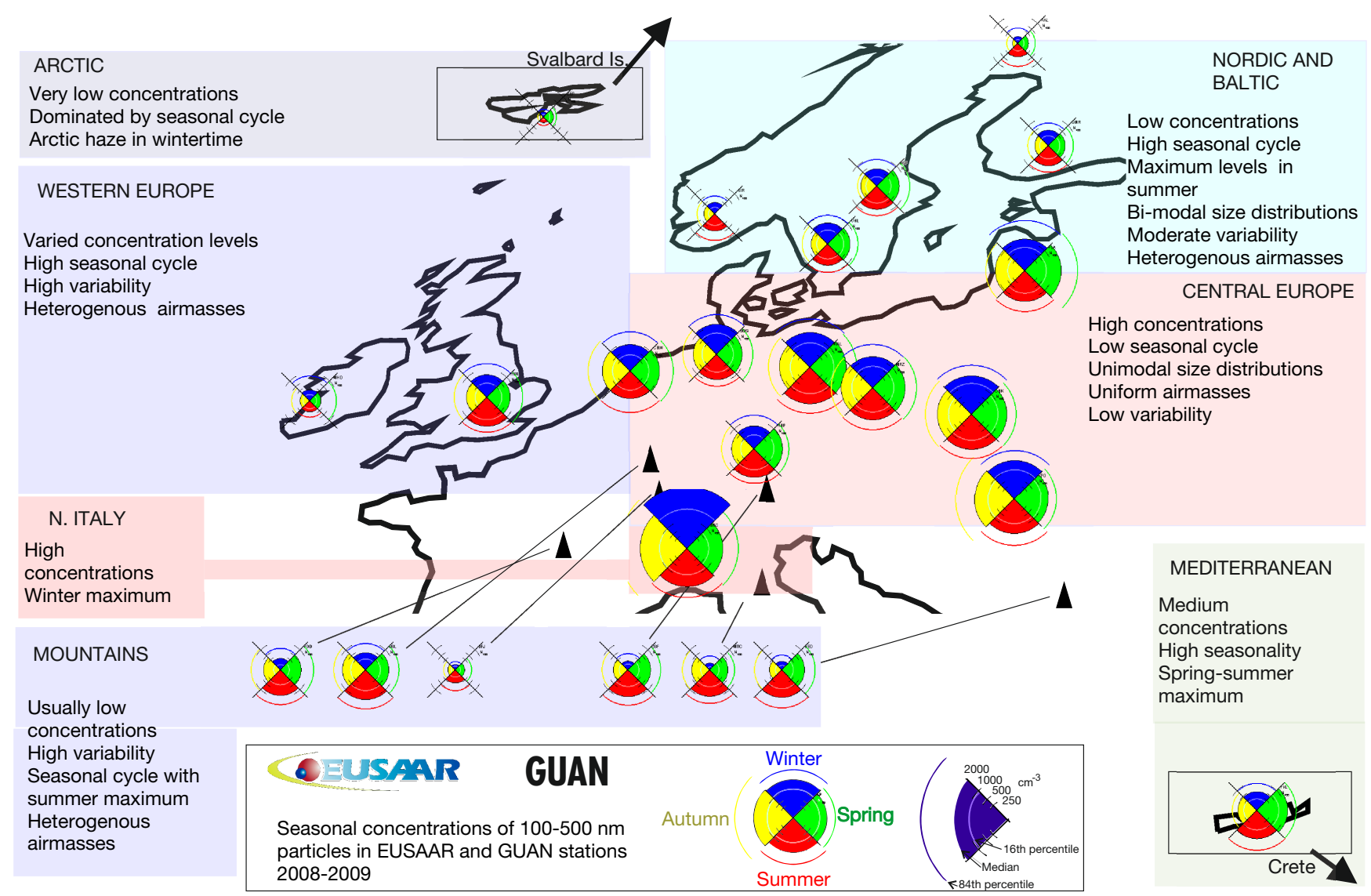

Fig. 15. Overview of EUSAAR and GUAN station measurements - spatial distribution of particle number concentrations on particle (in $\mathrm{cm}^{-3}$ STP). The coloured areas are relative to the median concentration observed in each season, and the lower and higher arcs show 16 th and 84 th percentile concentrations. The colours and location of the segments show different seasons. The locations of the stations are approximate. Stations ZEP (Arctic) and FKL (Mediterranean) are located in inserts.

micron aerosol physical properties and variability in Europe. Such information would be hard to achieve based on information collected from separately managed stations, especially if the instrumentation and data handling are not harmonized. The analysis in this paper shows that the aerosol concentrations in Europe are highly variable spatially. We consider both the spatial and temporal variations of the aerosol number concentrations in Europe to be generally much greater than instrumental uncertainties. The particle concentrations, derived statistics, size distribution functions and modal fitting parameters at the stations show groupings based on geographic location (see Fig. 15):

1. The "Central European Aerosol", observed at low-land stations from the Netherlands to Hungary showed low seasonal changes, high particles concentrations, almost unimodal median distributions and relatively low variability. The concentration histograms are practically log-normal and not strongly affected by diurnal variation. This aerosol type was observed the stations BOE,
WAL, MPZ, OBK and KPO, although some seasonal signal was observed in OBK. Stations HPB and SSL had many similarities with these stations, but due to their relatively high altitude they also showed similarities with mountain stations, including greater variability and skewed $N_{100}$ concentrations histograms. The station CBW in Netherlands has many features in common with the Central European stations and can be categorised in this group.

2. The "Northern European Aerosol", has clearly lower concentrations, with decreasing concentrations at higher latitudes. Although the similarities are not as obvious as in Central Europe, the stations are still similar enough in regards of seasonal and size distribution behaviour that these stations can be described by one type. The seasonal cycle has a strong effect on the particles in this region, and the overall variation is relatively large. The summer concentrations are usually greatest, especially for smaller particle sizes, which also affects the 
observed differences of day and night-time values due to differing length of day in the northern latitudes. The concentration distributions often show multiple modes, suggesting a combination of more polluted airmasses and cleaner air from the Arctic or Atlantic oceans. The stations included in this group were BIR, VHL, ASP and SMR. PAL has many similarities with other Nordic stations, but had even more extreme seasonal variation and thus had some parameters in common with Arctic aerosol concentrations and variability. The Baltic PLA station was only partially similar to the Nordic stations, with both concentration histograms and size distributions showing influence from multiple source areas of particles and some similarities in concentration levels with Central European aerosol.

3. "Mountain aerosol" which is characterized by episodes of extremely clean air, most probably from the free troposphere, mixed by episodes of relatively polluted airmasses, especially during daytime in summer. These changes of airmass produce complex, strongly skewed and very wide concentration histograms, with in many cases strong diurnal cycles. The Central European SSL and HPB stations were borderline mountain stations with some similarities with boundary layer Central European stations. The stations with this kind of aerosol were JFJ, BEO, ZSF and CMN.

For the other areas, the number of stations is too low to clearly distinguish the aerosol type in this way, as the spatial coverages of the stations are unknown. We can however state, that with greater uncertainty, the aerosol types are

4. "Arctic aerosol" with high seasonality, very low overall number concentrations and evidence of Arctic haze events during dark winter periods;

5. "North Italian aerosol" with very high number concentrations, especially during winter in accumulation mode and with a unimodal median particle number size distribution;

6. "Mediterranean aerosol" with medium number concentrations and maximum number concentrations during summer and spring; and

7. "Western European" aerosol with clear influence of multiple sources of aerosol (clean and polluted), and with a high seasonal cycle for smaller particle sizes. This grouping does not have high similarity between the stations.

The site categorisation developed by Henne et al. (2010) does not have extremely good agreement with aerosol properties studied in this paper, the underlying methodology does have potential also for aerosol studies. The site representability regarding some particle size ranges could be de- termined using a combination of methods: comparing station concentrations in a representable area and by observing the histogram widths, seasonality and number of modes visible. A more detailed generalization of the representability for aerosol number concentrations would require similar underlying methodology as Henne et al. (2010), probably with longer back-trajectories, including wet deposition as the main deposition proxy and by including secondary particle formation as a source of particle number concentrations. However, considering the difficulties of modelling wet deposition and secondary particle formation this could be a difficult task.

We have also shown that even though the aerosol number concentrations of Aitken and accumulation mode particles are generally related, there is significant variation in the ratio of concentrations of these two modes. Different aerosol and station types can be distinguished from these concentrations and this methodology has potential for further categorization of stations.

The measured aerosol number concentrations did not have strong weekly variance in the annual concentration histograms. The statistical tests done did not support statistically significant differences in $\mathrm{CCN}$-sized aerosol number concentrations between individual weekdays or between work-week and week-end. This result is different previous studies using particle mass or AOT as the aerosol tracer, where weekly variation was detected even in multi-year weekday means (Bäumer et al., 2008; Barmet et al., 2009).

The produced datasets are designed from the modelmeasurement comparison point-of-view. The datasets are available for the modellers in easy-to-use format for particle sizes which have potential for climate relevance. This dataset is a valuable comparison toolbox for the use of the global and regional modelling communities.

The main future lines of improvement of such European long-term studies is to make the coverage of the stations a more uniform. The lack of stations in Eastern Europe, and partially in the Mediterranean basin are clear open areas in this field of study. The only EUSAAR station on the Iberian Peninsula (MSY, Montseny) was not included in this study due lack of validated data for this period, but in future this will somewhat increase our knowledge of the Mediterranean size distributions in long-term basis.

The EUSAAR and GUAN networks are globally unique both in data quality and relatively dense network. Building a similar global network is a major undertaking, but would enable the community to efficiently characterize the aerosol number distribution, and thus improve the potential of characterizing the climate impacts of the aerosols in global boundary layer.

\section{Author contributions}

In author order (only initials used): AA had the original idea of the paper jointly with COD, did the data collection from 
Table 6. Modal fit parameters for median size distributions in the stations. $\sigma_{g}$ is the geometric standard deviation of the mode, $N_{m}$ is the mode number concentration, $\hat{d}_{p, m}$ is the geometric mean dry diameter of the mode and $R^{2}$ is the coefficient of determination between observed and fitted size distribution.

\begin{tabular}{|c|c|c|c|c|c|c|c|c|c|c|c|}
\hline \multirow[b]{2}{*}{ Station } & \multicolumn{4}{|c|}{ 1-Mode fit } & \multicolumn{7}{|c|}{ 2-Mode fit } \\
\hline & $\sigma_{g}$ & $\begin{array}{r}N_{m} \\
\left(\mathrm{~cm}^{-3}\right)\end{array}$ & $\begin{array}{l}\hat{d}_{p, m} \\
(\mathrm{~nm})\end{array}$ & $R^{2}$ & $\sigma_{g, m 1}$ & $\begin{array}{r}N_{m 1} \\
\left(\mathrm{~cm}^{-3}\right)\end{array}$ & $\begin{array}{r}\hat{d}_{p, m 1} \\
(\mathrm{~nm})\end{array}$ & $\sigma_{g, m 2}$ & $\begin{array}{r}N_{m 2} \\
\left(\mathrm{~cm}^{-3}\right)\end{array}$ & $\begin{array}{r}\hat{d}_{p, m 2} \\
(\mathrm{~nm})\end{array}$ & $R^{2}$ \\
\hline ASP & 2.12 & 1405 & 69 & 0.95 & 1.87 & 1233 & 64 & 1.36 & 144 & 222 & 0.99 \\
\hline BIR & 2.03 & 700 & 60 & 0.91 & 1.63 & 539 & 53 & 1.41 & 142 & 170 & 1.00 \\
\hline PAL & 2.57 & 337 & 58 & 0.84 & 1.71 & 221 & 48 & 1.45 & 81 & 176 & 0.99 \\
\hline PLA & 2.09 & 3281 & 80 & 1.00 & 2.04 & 3175 & 78 & 1.27 & 84 & 207 & 1.00 \\
\hline SMR & 2.32 & 1202 & 63 & 0.97 & 1.96 & 1008 & 57 & 1.36 & 144 & 201 & 1.00 \\
\hline VHL & 2.17 & 2069 & 61 & 0.97 & 1.86 & 1756 & 56 & 1.41 & 253 & 195 & 1.00 \\
\hline BOS & 2.77 & 5500 & 48 & 0.99 & 1.36 & 432 & 21 & 2.44 & 4710 & 57 & 1.00 \\
\hline KPO & 2.32 & 4353 & 81 & 0.98 & 2.20 & 2788 & 54 & 1.73 & 1590 & 134 & 1.00 \\
\hline OBK & 2.31 & 4183 & 87 & 0.97 & 2.26 & 2479 & 51 & 1.78 & 2019 & 131 & 1.00 \\
\hline HРB & 2.73 & 2173 & 66 & 0.96 & 2.39 & 1609 & 45 & 1.66 & 554 & 148 & 1.00 \\
\hline MPZ & 2.74 & 3941 & 65 & 0.99 & 2.49 & 3516 & 58 & 1.60 & 338 & 203 & 1.00 \\
\hline WAL & 2.51 & 4078 & 61 & 0.99 & 2.37 & 3837 & 58 & 1.38 & 175 & 194 & 1.00 \\
\hline $\mathrm{CBW}$ & 1.82 & 6352 & 48 & 0.98 & 1.40 & 1721 & 35 & 1.76 & 4450 & 60 & 0.99 \\
\hline HWL & 2.43 & 2568 & 49 & 0.98 & 2.06 & 2196 & 46 & 1.55 & 256 & 196 & 1.00 \\
\hline MHD & 5.00 & 717 & 30 & 0.82 & 1.79 & 303 & 35 & 1.70 & 152 & 174 & 0.99 \\
\hline FKL & 2.06 & 1613 & 99 & 0.99 & 1.94 & 1359 & 86 & 1.41 & 228 & 189 & 1.00 \\
\hline ISP & 2.24 & 6849 & 69 & 0.98 & 2.19 & 2828 & 31 & 1.87 & 4344 & 91 & 1.00 \\
\hline ZEP & 2.20 & 157 & 117 & 0.81 & 1.65 & 50 & 39 & 1.61 & 109 & 150 & 1.00 \\
\hline PDD & 2.57 & 1482 & 57 & 0.98 & 2.25 & 1223 & 48 & 1.54 & 207 & 147 & 1.00 \\
\hline SSL & 2.71 & 2109 & 62 & 0.96 & 2.32 & 1709 & 51 & 1.48 & 322 & 166 & 1.00 \\
\hline ZSF & 2.76 & 908 & 54 & 0.97 & 2.29 & 729 & 45 & 1.49 & 132 & 157 & 1.00 \\
\hline JFJ & 2.20 & 324 & 60 & 0.96 & 1.70 & 221 & 47 & 1.46 & 84 & 136 & 1.00 \\
\hline BEO & 2.16 & 871 & 90 & 0.97 & 1.76 & 514 & 60 & 1.53 & 330 & 156 & 1.00 \\
\hline $\mathrm{CMN}$ & 2.47 & 1005 & 69 & 0.95 & 1.98 & 716 & 52 & 1.50 & 237 & 157 & 1.00 \\
\hline
\end{tabular}

ready-made datasets in databank, programmed the analysis, wrote most of the article, decided on the chosen metrics, methods of analysis and made the figures and tables. AW was partly in charge of MPZ and GUAN datasets, was the manager of the size distribution measurement planning, standards and intercalibration. He also contributed to writing of the manuscript. PL was the project manager of the EUSAAR network, took a part on the representability analysis and contributed to PDD station data. He also contributed to writing of the manuscript. AMF was responsible for the database, data format definitions and other characteristics of stations. KS contributed to writing of the manuscript and was responsible for PDD dataset. WB was in charge of GUAN measurements and the data from MPZ station. EW and UB were in charge of JFJ measurements and contributed to writing of the manuscript. VZ was responsible for calibration of station OBK, SMPS and its CPC during workshops, installation of SMPS, its proper long-term operation, maintenance and enabling the data transfer to the tropos.de and EBAS databases. NZ did the statistical analysis of the SMPS data from Kosetice station, checked carefully data from the OBK station given in Figures and Tables and produced corrected versions of them. J-PP was responsible for the data from ISP station and he contributed significantly on the early version of the manuscript. AM was responsible for aerosol measurements at Monte Cimone station, she did the day-to-day upkeep and data collection and submission to EBAS; She also commented extensively on the manuscript. PT and $\mathrm{HCH}$ were responsible of the data from ZEP and ASP stations. MF was the instrument operator and took care of the daily maintenance of station BIR. NK, HL and EA were in charge of instrumentation and data handling from PAL station; EA also did the modal fitting. VU contributed for the measurements from station PRL. PPA contributed to day-to-day operation and data quality from SMR and KPO stations. ES is responsible for the aerosol measurements at the VHL station and designed the DMPS system together with AK. NM is the FKL station head investigator and NK was in charge of system maintaining, data collecting and analysis. IK was responsible of PLA station data. GK was responsible for the $\mathrm{KPO}$ station. GdL and BH were responsible for the CBW dataset and GdL commented extensively on the document. RMH manages the contract under which the HWL station operates and supervises the processing of the data. DCSB 
collates the data from the HWL station and conducts data analyses and interpretation. COD and SGJ were responsible for the MHD dataset and COD took a part in the early planning of this study. HF, KW, FM and LR were responsible of the GUAN aerosol measurements. MK was responsible of the design of SMR and KPO measurements and took a part in the early planning of the work.

All authors contributed to the final version of the document with their comments.

\section{Appendix A}

\section{Modal fits for median size distributions}

We fitted log-normal modes to the median size distributions of the stations. These help to demonstrate the modality of the aerosol population at each station. The fit was done only for particle sizes larger than $20 \mathrm{~nm}$ dry particle diameter to avoid the need of a third mode and to keep the size distribution measurements comparable. The was done at least-squares sense using either one or two log-normal modes of form

$\frac{d n}{d \log _{10} d_{p}}=\frac{N_{m}}{\sqrt{2 \pi} \log _{10}\left(\sigma_{g, m}\right)} \exp \left[-\frac{\left(\log _{10} d_{p}-\log _{10} \hat{d}_{p, m}\right)^{2}}{2\left(\log _{10}\left(\sigma_{g, m}\right)\right)^{2}}\right]$ (A1) where $N_{m}$ is the modal concentration $\left(\mathrm{cm}^{-3}\right), \sigma_{g, m}$ is the geometric standard deviation of the mode and $\hat{d}_{p, m}$ is the mode peak location (nm) (Heintzenberg, 1994).

The goodness of fit was determined by the coefficient of determination

$R^{2}=1-\frac{\sum_{i}^{N}\left(y_{i}-f_{i}\right)^{2}}{\sum_{i}^{N}\left(y_{i}-\bar{y}\right)^{2}}$

where $N$ is the number of size bins used in the fit, $y_{i}$ are the measured size distribution function values for each bin, $\bar{y}$ is the mean measured size distribution function value and the $f_{i}$ are the size distribution function values derived from the fit for each bin.

Results of the mode fitting are in Table 6. The singlemode fits have a relatively large $R^{2}$ parameter $(>0.95)$ for Central European stations, PLA, HWL, CBW, FKL, ISP and mountain stations. The single mode fit did less well on the more bimodal aerosol populations of the Nordic stations, MHD and ZEP, resulting in extremely wide geometric standard deviations. The bimodal fitting parameters have very large $R^{2}$ values suggesting that two modes give a very good approximation of annual median size distribution function. The bimodality of the station ZEP distribution is however somewhat misleading, as the two modes rarely appear at the same time (see Section 3.2 for details). The peak diameter of the smaller (Aitken) mode was for most stations around $50-60 \mathrm{~nm}$, with the exception of BOS, where the smaller mode was fitted on observed nucleation mode, and the larger mode was more representative of traditional Aitken mode. At CBW and ISP, the two modes were strongly overlapping. The geometric standard deviations of 1-mode fit were generally large, with an exception in the case of station CBW, where the geometric standard deviation was almost identical in 1-mode and 2-mode fits.

Not surprisingly, two mode fits improve the goodness of fit. The median size distribution of most of the stations can however be rather well captured by a unimodal fit. At the Nordic stations, Arctic ZEP station and marine-influenced MHD station the bimodal fit is most likely needed to capture the overall shape of the distribution.

\section{Appendix B}

\section{$N_{250}$ concentrations}

The instrumentation used in this article have generally greater discrepancies with the reference instrument on particles with diameters larger than $200 \mathrm{~nm}$, due to usually low number concentrations in that range. There however are stations where the concentration of these particles is enough for a metric of this range to be relevant.

We calculated $N_{250}$ concentrations for particles between 250 and $500 \mathrm{~nm}$ diameter similarly as other integrated concentrations in this paper. The resulting histograms are shown in Fig. 16. The overall picture is that the $N_{250}$ concentrations are of greater variability than $N_{100}$. The Nordic station seasonality is similar as $N_{100}$, although the summer maximum is of much less prominence compared to $N_{100}$ histograms. The Central European stations had a similar histogram shape seasonality as in $N_{100}$ cases, although with approximately one order of magnitude less concentration, suggesting that the particles between 100 and $250 \mathrm{~nm}$ have similar sources and sinks as particles larger than $250 \mathrm{~nm}$ in Central Europe. The Western Europe, North Italy, Mediterranean and Arctic concentration histogram shapes were also very similar to $N_{100}$, although the greater concentration maxima of MHD was much less visible in the $N_{250}$ distribution. This indicates that the polluted mode of the MHD station is mainly from particles between 100 and $250 \mathrm{~nm}$ of diameter. The mountain stations had significantly higher variability in $N_{250}$, especially for the lowest concentrations.

The results generally show similar patterns compared to $N_{100}$ concentrations, even though the comparability between instruments is not so good as with other measurements. The $N_{250}$ histograms can still be useful, as they represent a significant fraction of potential CCN sized aerosol number especially on the relatively high concentration stations in Central Europe and Northern Italy. The usability of this metric in the lowest end of the concentration scale is limited, as the instrumental noise starts to affect the concentrations significantly, probably explaining part of the greater variability of the $N_{250}$ concentrations compared to other properties in this article. 

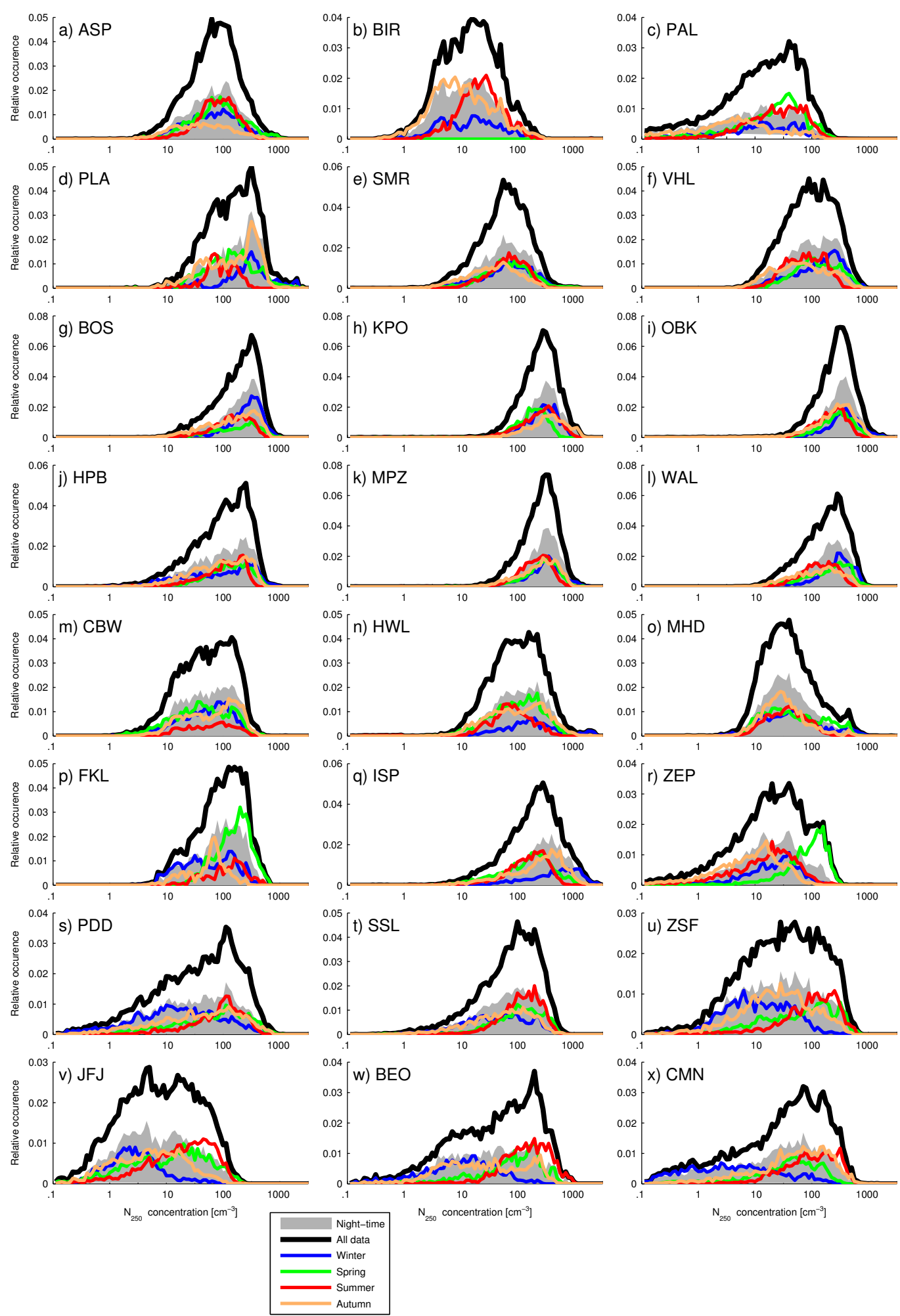

Fig. 16. Histograms of $N_{250}$ concentrations in the stations. See Fig. 9 for nomenclature. Note the different scale on x-axis compared to Figs. 9-11. 


\section{Appendix C}

\section{Data availability and suggestions on data usage}

The datasets used in this paper are available directly as timeseries from the graphical interface at NILU EMEP database (EBAS) at address http://ebas.nilu.no/. The data presented in this article (histograms, seasonal profiles, etc) are also stored on publicly available server at http://www.atm.helsinki.fi/ eusaar/.

The data format of data presented in this article is ASCII text files, with a README file to explain the data structuring used. The datasets are provided for the following aerosol and supporting data groups:

- Standard size intervals where the size-dependent data are interpolated

- Standard time-axis for using the data (hourly)

- Station-specific "bad data" vectors, to possibly remove those same periods from modelled datasets

- Aerosol size distribution medians and percentiles persize-bin basis. The data is interpolated to standard size intervals (above) and presented with total, seasonal, daytime, night-time and ECHAM5-HAM sampling. This data is also available separately for 2008 and 2009.

- $N_{30-50}, N_{50}$ and $N_{100}$ concentration histograms for identical logarithmically evenly distributed concentration bins. The data is separated for total, seasonal, daytime, night-time and ECHAM5-HAM sampling.

For a successful data-measurement comparison, we suggest that the modeller will at least consider the following steps

1. Make sure you are comparing similar concentrations. Change the modelled concentrations to particle number in $\mathrm{cm}^{-3}$ under STP condition air and model the aerosol to low relative humidity conditions to be comparable with measurement techniques and conditions of this paper

2. Use long enough datasets to be comparable with the seasonal data provided in this paper. Although e.g. individual days might be outside of the 16th-84th percentile range provided in most figures here, they still might be perfectly reasonable for the most polluted episodes of the station.

3. Do not only compare median concentrations or size ranges, but instead use histogram information to get the statistical distributions of the particles correct. The cloud generation in the model will then at least sample from similar size distributions of potential CCNs.
4. If the histogram has multiple peaks, it often suggests multiple sources of aerosols, e.g. airmasses from different source areas. If your modelled data lacks one of the peaks detected, the reason might also be on the model advection scheme instead of aerosol processes or sources.

5. Compare all the available size ranges provided. Getting a single range, e.g. $N_{50}$ correct can easily be interpreted as getting the CCN-sized aerosol "right" in statistical sense, but can be "correct" from wrong reasons. Inclusion of the three main provided size ranges gives at least a more comparable set of different processes related to aerosols which the model has to get correct. The histograms of $N_{250}$ (Appendix B) have higher possibility of error, but can be useful as tracers of the above $100 \mathrm{~nm}$ sub-micron aerosol.

6. In comparing with mountain sites, consider the effect of local topography, which is not usually well described in the large-scale (and often a large-grid-size) models. The local wind effects will move polluted boundary layer air to mountain sites, which can make comparison difficult. In these cases, compare the histograms carefully, with special attention to the lower concentration "tails" of the mountain site concentration profiles.

7. In comparing with Arctic site, the effect of Arctic haze can dominate the aerosol distribution during wintertime.

8. A scatterplot of "Aitken" and "accumulation" mode concentrations can also be useful in trying to see if the modelled surface concentrations are similar to the measured ones (see Fig. 13). A way to quickly calculate approximate modal concentrations from concentrations, approximate the Aitken mode concentration by $N_{30-100}=N_{50}-N_{100}+N_{30-50}$ and an accumulation mode with $N_{100}$. The actual method to draw the "83 percent of observations lines" is as follows:

(a) Assume $n$ co-incident observations of $N_{30-100}$ and $N_{100}$. Divide concentrations axes into $n_{s}$ logarithmically even intervals between concentrations of 1 and $100000 \mathrm{~cm}^{-3}$. Denote the interval borders as $K_{i}$ and $L_{j}\left(i=j=1 \ldots n_{s}+1\right)$ for $N_{30-100}$ and $N_{100}$, respectively.

(b) Calculate the concentration density function for each size interval $C(i, j)$ :

$C(i, j)=\sum_{k=1}^{n} \Lambda\left(N_{30-100}(k), N_{100}(k), K_{i}, K_{i+1}, L_{j}, L_{j+1}\right)(\mathrm{C} 1)$

for all $i=1 \ldots n_{s}$ and $j=1 \ldots n_{s}$, and the summation function $\Lambda$ is defined as

$$
\begin{aligned}
& \Lambda\left(C_{1}, C_{2}, M_{11}, M_{12}, M_{21}, M_{22}\right) \\
& =\left\{\begin{array}{l}
1, \text { if } M_{11}<C_{1} \leq M_{12} \text { and } M_{21}<C_{2} \leq M_{22} \\
0, \text { otherwise }
\end{array}\right.
\end{aligned}
$$


(c) Map $C(i, j) 2 \mathrm{D}$ array into a single-dimension array $C_{s 1}(l)$

$C(i, j)=C_{s 1}(l), \forall i, j$

where the $l=i+(j-1) n_{s}=1 \ldots n_{s}^{2}$. Then sort the densities in numerical order (from largest density to lowest)

$C_{s}=\operatorname{sort}\left(C_{s 1}\right) \Rightarrow C_{s}(l) \geq C_{s}(l+1), \forall l$

(d) Find value of $l_{m} \in l$ where the cumulative sum of the $C_{s}$ is closest to 83 percent of the number of observations

$$
\left|0.83 n-\sum_{o=1}^{l_{m}} C_{s}(o)\right|=\min \left(\left|0.83 n-\sum_{o=1}^{l} C_{S}(o)\right|\right)
$$

(e) Use this value to draw a contour around regions of $C(i, j)>C_{s}\left(l_{m}\right)$. We used value of 30 for $n_{s}$, but testing showed that the main properties of the contours were not sensitive to doubling of $n_{s}$. The method could also be described in writing as

i. Create equal log separated grid of concentrations

ii. See how many observations go to each grid box

iii. Sum from the greatest observation density grid box towards lower concentration grid boxes until you end up with 83 percent of the observations. Draw a contour around these grid-boxes.

As a note on the sampling frequency, several large-scale models do not automatically output information on hourly basis for performance reasons. As an example ECHAM5HAM global climate model outputs data on every six hours UTC (00:00 h, 06:00 h, 12:00 h and 18:00 h) as instantaneous concentrations. As we used hourly means in our study, we could only approximate this imperfect sampling by using the hourly means of the hours starting with the same UTC hours. Only few of the stations seemed to be sensitive to this change of sampling, the maximum error of annual median being in all size ranges less than $5 \%$, with most stations having error less that $2 \%$. The error from this sampling can raise as high as $14 \%$ for 5 th percentile of $N_{100}$ on mountain stations, showing that the mountain stations can be sensitive to non-ideal sampling. Overall the effect on middle percentiles shown in this article are minimal. The results are well in line with the extremely high autocorrelation rates of the concentrations, suggesting that small variations in sampling or short-period gaps in the data do not significantly affect the annual or seasonal mean concentrations.

In preparing this paper, we have tried to take into account many of the uncertainties and corrections to the datasets, but especially when using timeseries data directly from the NILU EBAS database, a contact to the station representative is recommended (and in the case of some of the datasets, even required). All EBAS datasets have contact information of the person responsible for the data quality in the meta-data headers of the data files. This contact is very important not only for the data user, who gets information on the dataset and possible caveats of use of the data, but also for the data provider who will then know how and how much the data is used and can thus partly justify the resources used for the upkeep of the station.

Acknowledgements. This work was performed in the framework of the Research Infrastructure Action under the FP6 "Structuring the European Research Area" Programme, EUSAAR Contract no. RII3-CT-2006-026140. The work has been partly funded by FP6 Integrated project EUCAARI, Contract no. 36833. The financial support by the Academy of Finland Centre of Excellence program (project no. 1118615) is gratefully acknowledged. The authors thank the Italian Air Force for the fruitful collaboration at Mt. Cimone and SHARE Project (Ev-K2-CNR) for the financial support. Authors wish to thank Mila Vana, head of the station KOS for his support of EUSAAR measurements. The Harwell station is operated with financial support from the UK Department for Environment, Food and Rural Affairs. The UK National Centre for Atmospheric Science is funded by the Natural Environment Research Council. The authors acknowledge the Swedish Environmental Monitoring Program. Thanks to the Norwegian Polar Institute and the technicians that help maintaining the equipment at Zeppelin station. Contributions from OPGC, French National Agency (ANR) and ADEME to support measurements at PDD is greatly acknowledged.

Edited by: I. Riipinen

\section{References}

Albrecht, B. A.: Aerosol, cloud microphysics, and fractional cloudiness, Science, 245, 1227-1230, 1989.

Amunsen, C., Hanssen, J., Semb, A., and Steinnes, E.: Long-range atmospheric transport of trace elements to southern Norway, Atmos. Environ. A-Gen., 26, 1309-1324, doi:10.1016/09601686(92)90391-W, 1992.

Andreae, M. and Rosenfeld, D.: Aerosol-cloud-precipitation interactions. Part 1. The nature and sources of cloud-active aerosols, Earth-Sci. Rev., 89, 13-41, doi:10.1016/j.earscirev.2008.03.001, 2008.

Asmi, E., Sipilä, M., Manninen, H. E., Vanhanen, J., Lehtipalo, K., Gagn, S., Neitola, K., Mirme, A., Mirme, S., Tamm, E., Uin, J., Komsaare, K., Attoui, M., and Kulmala, M.: Results of the first air ion spectrometer calibration and intercomparison workshop, Atmos. Chem. Phys., 9, 141-154, doi:10.5194/acp-9-141-2009, 2009.

Barmet, P., Kuster, T., Muhlbauer, A., and Lohmann, U.: Weekly cycle in particulate matter versus weekly cycle in precipitation over Switzerland, J. Geophys. Res., 114, D05206, doi:10.1029/2008JD011192, 2009.

Bäumer, D., Rinke, R., and Vogel, B.: Weekly periodicities of Aerosol Optical Thickness over Central Europe - evidence of an anthropogenic direct aerosol effect, Atmos. Chem. Phys., 8, 83-90, doi:10.5194/acp-8-83-2008, 2008. 
Birmili, W., Berresheim, H., Plass-Dülmer, C., Elste, T., Gilge, S., Wiedensohler, A., and Uhrner, U.: The Hohenpeissenberg aerosol formation experiment (HAFEX): a longterm study including size-resolved aerosol, $\mathrm{H}_{2} \mathrm{SO}_{4}, \mathrm{OH}$, and monoterpenes measurements, Atmos. Chem. Phys., 3, 361-376, doi:10.5194/acp-3-361-2003, 2003.

Birmili, W., Weinhold, K., Nordmann, S., Wiedensohler, A., Spindler, G., Müller, K., Herrmann, H., Gnauk, T., Pitz, M., Cyrys, J., Flentje, H., Nickel, C., Kulhbusch, T., Lschau, G., Haase, D., Meinhardt, F., Schwerin, A., Ries, L., and Wirtz, K.: Atmospheric aerosol measurements in the German Ultrafine Aerosol Network (GUAN), - Part 1: Soot and particle number distributions, Gefahrst. Reinhalt. L., 69, 137-145, 2009a.

Birmili, W., Ries, L., Sohmer, R., Anastou, A., Sonntag, A., Knig, K., and Levin, I.: Fine and ultrafine aerosol particles at the GAW station Schneefernerhaus/Zugspitze, Gefahrst. Reinhalt. L., 69, 31-35, 2009b.

Central Intelligence Agency: The World Factbook 2009, Central Intelligence Agency, Washington, DC, USA, 2009.

Charlson, R. J.: Atmospheric visibility related to aerosol mass concentration: review, Envir. Sci. Tech., 3, 913-918, doi:10.1021/es60033a002, 1969.

Charlson, R. J., Schwartz, S. E., Hales, J. M., Cess, R. D., Coakley, J. A., Hansen, J. E., and Hofmann, D. J.: Climate forcing by anthropogenic aerosols, Science, 255, 423-430, 1992.

Charron, A., Birmili, W., and Harrison, R. M.: Factors influencing new particle formation at the rural site, Harwell, United Kingdom, J. Geophys. Res., 112, 14210, doi:10.1029/2007JD008425, 2007.

Charron, A., Birmili, W., and Harrison, R. M.: Fingerprinting particle origins according to their size distribution at a UK rural site, J. Geophys. Res., 113, 07 202, doi:10.1029/2007JD008562, 2008.

Cristofanelli, P., Bonasoni, P., Carboni, G., Calzolari, F., Casarola, L., Sajani, S. Z., and Santaguida, R.: Anomalous high ozone concentrations recorded at a high mountain station in Italy in summer 2003, Atmos. Environ., 41, 1383-1394, doi:10.1016/j.atmosenv.2006.10.017, 2007.

Dahmann, D., Riediger, G., Schlatter, J., Wiedensohler, A., Carli, S., Graff, A., Grosser, M., Hojgr, M., Horn, H.-G., Jing, L., Matter, U., Monz, C., Mosimann, T., Stein, H., Wehner, B., and Wieser, U.: Intercomparison of mobility particle sizers (MPS), Gefahrst. Reinhalt. L., 61, 423-428, 2001.

Dal Maso, M., Hyvärinen, A., Komppula, M., Tunved, P., Kerminen, V.-M., Lihavainen, H., Viisanen, Y., Hansson, H.-C., and Kulmala, M.: Annual and interannual variation in boreal forest aerosol particle number and volume concentration and their connection to particle formation, Tellus B, 60, 495-508, doi:10.1111/j.1600-0889.2008.00366.x, 2008.

Donaldson, K., Li, X., and MacNee, W.: Ultrafine (nanometre) particle mediated lung injury, J. Aerosol Sci., 29, 553-560, 1998.

Duffett-Smith, P.: Practical Astronomy with your calculator, University of Cambridge, Cambridge, UK, 3 edn., 1988.

Dusek, U., Frank, G. P., Hildebrandt, L., Curtius, J., Schneider, J., Walter, S., Chand, D., Drewnick, F., Hings, S., Jung, D., Borrmann, S., and Andreae, M. O.: Size matters more than chemistry for cloud-nucleating ability of aerosol particles, Science, 312, 1375-1378, doi:10.1126/science.1125261, 2006.

Engler, C., Rose, D., Wehner, B., Wiedensohler, A., Brüggemann, E., Gnauk, T., Spindler, G., Tuch, T., and Birmili, W.: Size distri- butions of non-volatile particle residuals $\left(\mathrm{D}_{p}<800 \mathrm{~nm}\right)$ at a rural site in Germany and relation to air mass origin, Atmos. Chem. Phys., 7, 5785-5802, doi:10.5194/acp-7-5785-2007, 2007.

Fischer, H., Kormann, R., Klüpfel, T., Gurk, Ch., Königstedt, R., Parchatka, U., Mühle, J., Rhee, T. S., Brenninkmeijer, C. A. M., Bonasoni, P., and Stohl, A.: Ozone production and trace gas correlations during the June 2000 MINATROC intensive measurement campaign at Mt. Cimone, Atmos. Chem. Phys., 3, 725-738, doi:10.5194/acp-3-725-2003, 2003.

Gruening, C., Adam, M., Cavalli, F., Cavalli, P., Dell'Acqua, A., Martins Dos Santos, S., Pagliari, V., Roux, D., and Putaud, J.-P.: JRC Ispra EMEP - GAW Regional Station for Atmos. Res. 2008 Report, Tech. Rep. JRC55382, European Commission, http://publications.jrc.ec.europa.eu/repository/handle/ 111111111/538, 2009.

Hari, P. and Kulmala, M.: Station for Measuring EcosystemAtmosphere Relations (SMEAR II), Boreal Env. Res., 10, 315322, 2005.

Haywood, J. and Boucher, O.: Estimates of the direct and indirect radiative forcing due to tropospheric aerosols: A review, Rev. Geophys., 38, 513-543, 2000.

Heintzenberg, J.: Properties of the Log-Normal Particle Size Distribution, Aerosol Science and Technology, 21, 46-48, doi:10.1080/02786829408959695, 1994.

Helsper, C., Horn, H. G., Schneider, F., Wehner, B., and Wiedensohler, A.: Intercomparison of five mobility size spectrometers for measuring atmospheric submicrometer aerosol particles, Gefahrst. Reinhalt. L., 68, 475-481, 2008.

Bäumer, D., Rinke, R., and Vogel, B.: Weekly periodicities of Aerosol Optical Thickness over Central Europe - evidence of an anthropogenic direct aerosol effect, Atmos. Chem. Phys., 8, 8390, doi:10.5194/acp-8-83-2008, 2008.

Henning, S., Weingartner, E., Schmidt, S., Wendish, M., Gäggeler, and H. W Baltensperger, U.: Size-dependent aerosol activation at the high-alpine site Jungfraujoch (3580 m a.s.1.), Tellus B, 54, 82-95, doi:10.1034/j.1600-0889.2002.00299.x, 2002.

Higgins, J. J.: Introduction to modern nonparametric statistics, Brooks/Cole, SBN: 978-0534387754 USA, 2004.

Hinds, W. C.: Aerosol Technology, Wiley-Interscience, 2 edn., ISBN:978-0471194101, 19 January 1999, New York, USA, 1999.

Hoet, P. H., Brüske-Hohlfeld, I., and Salata, O. V.: Nanoparticles known and unknown health risks, Journal of Nanobiotechnology, 2, 12, doi:10.1186/1477-3155-2-12, 2004.

Hoppel, W. A. and Frick, G. M.: Submicron aerosol size distributions measured over the tropical and south pacific, Atmos. Environ. A-Gen., 24(3), 645-659, 1990.

Horvath, H.: Atmospheric light absorption - a review, Atmos. Environ. Part A, General Topics, 27, 293-317, doi:10.1016/09601686(93)90104-7, first Ibero-American Conference on the Atmos. Environ., CIAMAA91/ACAE91, 1993.

Imhof, D., Weingartner, E., Prévôt, A. S. H., Ordóñez, C., Kurtenbach, R., Wiesen, P., Rodler, J., Sturm, P., McCrae, I., Ekstrm, M., and Baltensperger, U.: Aerosol and $\mathrm{NO}_{\mathrm{x}}$ emission factors and submicron particle number size distributions in two road tunnels with different traffic regimes, Atmos. Chem. Phys., 6, 22152230, doi:10.5194/acp-6-2215-2006, 2006.

Jennings, S., O'Dowd, C., O'Connor, T., and McGovern, F.: Physical characteristics of the ambient aerosol at Mace Head, 
Atmos. Environ. A-Gen., 25, 557-562, doi:10.1016/09601686(91)90052-9, 1991.

Jones, A., Roberts, D. L., and Slingo, A.: A climate model study of indirect radiative forcing by anthropogenic aerosols, Nature, 370, 450-453, 1994.

Jurányi, Z., Gysel, M., Weingartner, E., Bukowiecki, N., Kammermann, L., and Baltensperger, U.: 17-month climatology of the cloud condensation nuclei number concentration at the high alpine site Jungfraujoch, J. Geophys. Res., 116, D10204, doi:10.1029/2010JD015199 2011.

Kerminen, V., Lihavainen, H., Komppula, M., Viisanen, Y., and Kulmala, M.: Direct observational evidence linking atmospheric aerosol formation and cloud droplet activation, Geophys. Res. Lett., 32, L14803, doi:10.1029/2005GL023130, 2005.

Khlystov, A., Kos, G. P. A., ten Brink, H. M., Mirme, A., Tuch, T., Roth, C., and Kreyling, W. G.: Comparability of three spectrometers for monitoring urban aerosol, Atmos. Environ., 35, 20452051, doi:10.1016/S1352-2310(00)00478-7, 2001.

Kiss, G., Varga, B., Galambos, I., and Ganszky, I.: Characterization of water-soluble organic matter isolated from atmospheric fine aerosol, J. Geophys. Res., 107, 8339-8347, doi:10.1029/2001JD000603, 2002.

Kristensson, A., Dal Maso, M., Swietlicki, E., Hussein, T., Zhou, J., Kerminen, V.-M., and Kulmala, M.: Characterization of new particle formation events at a background site in Southern Sweden: relation to air mass history, Tellus B, 60, 330-344, doi:10.1111/j.1600-0889.2008.00345.x, 2008.

Kruskal, W. H. and Wallis, W. A.: Use of Ranks in One-Criterion Variance Analysis, J. Am. Stat. Assoc., 47, 583-621, 1957.

Kulmala, M., Hämeri, K., Aalto, P. P., Mäkelä, J. M., Pirjola, L., Nilsson, E. D., Buzorius, G., Rannik, Ü., Dal Maso, M., Seidl, W., Hoffmann, T., Janson, R., Hansson, H.-C., Viisanen, Y., Laaksonen, A., and O'Dowd, C. D.: Overview of the international project on biogenic aerosol formation in the boreal forest (BIOFOR), Tellus B, 53, 324-343, 2001.

Kulmala, M., Asmi, A., Lappalainen, H. K., Carslaw, K. S., Pöschl, U., Baltensperger, U., Hov, Ø., Brenquier, J.-L., Pandis, S. N., Facchini, M. C., Hansson, H.-C., Wiedensohler, A., and O'Dowd, C. D.: Introduction: European Integrated Project on Aerosol Cloud Climate and Air Quality interactions (EUCAARI) - integrating aerosol research from nano to global scales, Atmos. Chem. Phys., 9, 2825-2841, doi:10.5194/acp-9-2825-2009, 2009.

Laden, F., Schwartz, J., Speizer, F. E., and Dockery, D. W.: Reduction in Fine Particulate Air Pollution and Mortality: Extended Follow-up of the Harvard Six Cities Study, Am. J. Respir. Crit. Care Med., 173, 667-672, doi:10.1164/rccm.200503-443OC, 2006.

Laj, P., Klausen, J., Bilde, M., Plass-Duelmer, C., Pappalardo, G., Clerbaux, C., Baltensperger, U., Hjorth, J., Simpson, D., Reimann, S., Coheur, P.-F., Richter, A., Maziere, M. D., Rudich, Y., McFiggans, G., Torseth, K., Wiedensohler, A., Morin, S., Schulz, M., Allan, J., Attie, J.-L., Barnes, I., Birmili, W., Cammas, J., Dommen, J., Dorn, H.-P., Fowler, D., Fuzzi, S., Glasius, M., Granier, C., Hermann, M., Isaksen, I., Kinne, S., Koren, I., Madonna, F., Maione, M., Massling, A., Moehler, O., Mona, L., Monks, P., Muller, D., Müller, T., Orphal, J., Peuch, V.-H., Stratmann, F., Tanre, D., Tyndall, G., Riziq, A. A., Roozendael, M. V., Villani, P., Wehner, B., Wex, H., and Zardin, A.: Mea- suring atmospheric composition change, Atmos. Environ., 43, 5351-5414, doi:10.1016/j.atmosenv.2009.08.020, 2009.

Lihavainen, H., Kerminen, V.-M., Komppula, M., Hyvärinen, A.-P., Laakia, J., Saarikoski, S., Makkonen, U., Kivekäs, N., Hillamo, R., Kulmala, M., and Viisanen, Y.: Measurements of the relation between aerosol properties and microphysics and chemistry of low level liquid water clouds in Northern Finland, Atmos. Chem. Phys., 8, 6925-6938, doi:10.5194/acp-8-6925-2008, 2008.

Lin, H. and Leaitch, W. R.: Development of an in-cloud aerosol activation parameterization for climate modelling, in: Proceedings of the WMO Workshop on Measurement of Cloud Properties for Forecasts of Weather, Air Quality and Climate, 328-335, World Meteorol. Organ, Geneva, 1997.

Lohmann, U. and Feichter, J.: Global indirect aerosol effects: a review, Atmos. Chem. Phys., 5, 715-737, doi:10.5194/acp-5-7152005, 2005.

Makkonen, R., Asmi, A., Korhonen, H., Kokkola, H., Järvenoja, S., Räisänen, P., Lehtinen, K. E. J., Laaksonen, A., Kerminen, V.M., Järvinen, H., Lohmann, U., Bennartz, R., Feichter, J., and Kulmala, M.: Sensitivity of aerosol concentrations and cloud properties to nucleation and secondary organic distribution in ECHAM5-HAM global circulation model, Atmos. Chem. Phys., 9, 1747-1766, doi:10.5194/acp-9-1747-2009, 2009.

Manninen, H. E., Nieminen, T., Asmi, E., Gagné, S., Häkkinen, S., Lehtipalo, K., Aalto, P., Vana, M., Mirme, A., Mirme, S., Hõrrak, U., Plass-Dülmer, C., Stange, G., Kiss, G., Hoffer, A., Töro, N., Moerman, M., Henzing, B., de Leeuw, G., Brinkenberg, M., Kouvarakis, G. N., Bougiatioti, A., Mihalopoulos, N., O’Dowd, C., Ceburnis, D., Arneth, A., Svenningsson, B., Swietlicki, E., Tarozzi, L., Decesari, S., Facchini, M. C., Birmili, W., Sonntag, A., Wiedensohler, A., Boulon, J., Sellegri, K., Laj, P., Gysel, M., Bukowiecki, N., Weingartner, E., Wehrle, G., Laaksonen, A., Hamed, A., Joutsensaari, J., Petäjä, T., Kerminen, V.-M., and Kulmala, M.: EUCAARI ion spectrometer measurements at 12 European sites - analysis of new particle formation events, Atmos. Chem. Phys., 10, 7907-7927, doi:10.5194/acp-10-79072010, 2010.

Marinoni, A., Cristofanelli, F., Calzolari, F., U., B., and Bonasoni, P.: Continous measurements of aerosol physical parameters at the Mt. Cimone GAW station (2165 m a.s.l., Italy), Sci. Total Environ., 391, 231-251, 2008.

Martinsson, B. G., Frank, G., Cederfeld, S.-I., Berg, O. H., Mentes, B., Papaspiropoulos, G., Swietlicki, E., Zhou, J., Flynn, M., Bower, K. N., Choularton, T. W., Mäkelä, J., Virkkula, A., and Van Dingenen, R.: Validation of very high cloud droplet number concentrations in air masses transported thousands of kilometers over the ocean, Tellus, 52B, 801-814, 2000.

MathWorks, Inc.: Matlab user manual for R2010a, http://www. mathworks.com/help/techdoc/index.html, 2010.

McFiggans, G., Artaxo, P., Baltensperger, U., Coe, H., Facchini, M. C., Feingold, G., Fuzzi, S., Gysel, M., Laaksonen, A., Lohmann, U., Mentel, T. F., Murphy, D. M., O’Dowd, C. D., Snider, J. R., and Weingartner, E.: The effect of physical and chemical aerosol properties on warm cloud droplet activation, Atmos. Chem. Phys., 6, 2593-2649, doi:10.5194/acp-6-2593-2006, 2006.

McGovern, F. M., Jennings, S. G., Connor, T. C., and Simmonds, P. G.: Aerosol and trace gas measurements during the Mace Head experiment, Atmos. Environ., 30, 3891-3902, 1996. 
McMurry, P. H.: A review of atmospheric aerosol measurements, Atmos. Environ., 34, 1959-1999, 2000.

Mihalopoulos, N., Stephanou, E., Pilitsidis, S., Kanakidou, M., and Bousquet, P.: Atmospheric aerosol composition above the Eastern Mediterranean region, Tellus, 49B, 314-326, 1997.

Nojarov, P., Ivanov, P., Kalapov, I., Penev, I., and Drenska, M.: Connection between ozone concentration and atmosphere circulation at peak Moussala, Theor. Appl. Climatol., 98, 201-208, doi:10.1007/s00704-009-0173-2, 2009.

Oberdörster, G., Oberdörster, E., and Oberdörster, J.: Nanotoxicology: An Emerging Discipline Evolving from Studies of Ultrafine Particles, Environ. Health Persp., 113, 7, doi:10.1289/ehp.7339, 2005.

O’Dowd, C., Hämeri, K., Mäkelä, J., Pirjola, L., Kulmala, M., Jennings, S., Berresheim, H., Hansson, H.-C., de Leeuw, G., Kunz, G., Allen, A., Hewitt, C., Jackson, A., Viisanen, Y., and Hoffmann, T.: A dedicated study of New Particle Formation and Fate in the Coastal Environment (PARFORCE): Overview of objectives and achievements, J. Geophys. Res., 107, 8108, doi:10.1029/2001JD000555, 2002.

Petters, M. D. and Kreidenweis, S. M.: A single parameter representation of hygroscopic growth and cloud condensation nucleus activity - Part 2: Including solubility, Atmos. Chem. Phys., 8, 6273-6279, doi:10.5194/acp-8-6273-2008, 2008.

Philippin, S., Laj, P., and Putaud, J.-P., Wiedensohler, A., de Leeuw, G., Fjaeraa, A., Platt, U., Baltensperger, U., and Fiebig, M.: EUSAAR An Unprecedented Network of Aerosol Observation in Europe, Earozoru Kenkyu, 24, 78-83, 2009.

Pope, C. A. I. and Dockery, D. W.: Health Effects of Fine Particulate Air Pollution: Lines that Connect, JAPCA J. Air Waste Ma., 56, 709-742, 2006.

Pringle, K. J., Carslaw, K. S., Spracklen, D. V., Mann, G. M., and Chipperfield, M. P.: The relationship between aerosol and cloud drop number concentrations in a global aerosol microphysics model, Atmos. Chem. Phys., 9, 4131-4144, doi:10.5194/acp-94131-2009, 2009.

Raes, F., Bates, T., McGovern, F., and Van liedekerke, M.: the 2nd aerosol characterization experiment (ACE-2): general overview and main results, Tellus, 52B, 111-125, 2000.

Rodrguez, S., Van Dingenen, R., Putaud, J.-P., Dell'Acqua, A., Pey, J., Querol, X., Alastuey, A., Chenery, S., Ho, K.-F., Harrison, R., Tardivo, R., Scarnato, B., and Gemelli, V.: A study on the relationship between mass concentrations, chemistry and number size distribution of urban fine aerosols in Milan, Barcelona and London, Atmos. Chem. Phys., 7, 2217-2232, doi:10.5194/acp7-2217-2007, 2007.

Russchenberg, H. W. J., Bosveld, F., Swart, D. P. J., ten Brink, H., de Leeuw, G., Uijlenhoet, R., Arbesser-Rastburg, B., van der Marel, H., Ligthart, L., Boers, R., and Apituley, A.: Groundbased atmospheric remote sensing in The Netherlands; European outlook, IEICE Transactions on Communications, E88-B, 22522258, doi:10.1093/ietcom/e88-b.6.2252, 2005.

Sager, T. and Castranova, V.: Surface area of particle administered versus mass in determining the pulmonary toxicity of ultrafine and fine carbon black: comparison to ultrafine titanium dioxide, Particle and Fibre Toxicology, 6, 15, doi:10.1186/1743-8977-615, 2009.

Sellegri, K., Laj, P., Dupuy, R., Legrand, M., Preunkert, S., and Putaud, J.-P.: Size-dependent scavenging efficiencies of mul- ticomponent atmospheric aerosols in clouds, J. Geophys. Res., 108, 4334, doi:10.1029/2002JD002749, 2003.

Sihto, S.-L., Mikkilä, J., Vanhanen, J., Ehn, M., Liao, L., Lehtipalo, K., Aalto, P. P., Duplissy, J., Petäjä, T., Kerminen, V.-M., Boy, M., and Kulmala, M.: Seasonal variation of CCN concentrations and aerosol activation properties in boreal forest, Atmos. Chem. Phys. Discuss., 10, 28231-28272, doi:10.5194/acpd-10-282312010, 2010.

Spindler, G., Brüggemann, E., Gnauk, T., Grüner, A., Müller, K., and Herrmann, H.: A four-year size-segregated characterization study of particles $\mathrm{PM} 10, \mathrm{PM}_{2.5}$ and $\mathrm{PM}_{1}$ depending on air mass origin at Melpitz, Atmos. Environment, 44, 164-173, 2010.

Spracklen, D. V., Pringle, K. J., Carslaw, K. S., Chipperfield, M. P., and Mann, G. W.: A global off-line model of size-resolved aerosol microphysics: II. Identification of key uncertainties, Atmos. Chem. Phys., 5, 3233-3250, doi:10.5194/acp-5-3233-2005, 2005.

Stevens, B. and Feingold, G.: Untangling aerosol effects on clouds and precipitation in a buffered system, Nature, 461, 607-613, doi:10.1038/nature08281, 2009.

Ström, J., Umegård, J., Tørseth, K., Tunved, P., Hansson, H. C., Holmn, K., Wismann, V., Herber, A., and König-Langlo, G.: One year of particle size distribution and aerosol chemical composition measurements at the Zeppelin Station, Svalbard, March 2000-March 2001, Phys. Chem. Earth, Parts A/B/C, 28, 11811190, doi:10.1016/j.pce.2003.08.058, 2003.

Tunved, P., Hansson, H.-C., Kulmala, M., Aalto, P., Viisanen, Y., Karlsson, H., Kristensson, A., Swietlicki, E., Dal Maso, M., Strm, J., and Komppula, M.: One year boundary layer aerosol size distribution data from five nordic background stations, Atmos. Chem. Phys., 3, 2183-2205, doi:10.5194/acp-3-2183-2003, 2003.

Tunved, P., Ström, J., and Hansson, H.-C.: An investigation of processes controlling the evolution of the boundary layer aerosol size distribution properties at the Swedish background station Aspvreten, Atmos. Chem. Phys., 4, 2581-2592, doi:10.5194/acp-4-2581-2004, 2004.

Twomey, S. A.: Pollution and the Planetary albeno, Atmos. Environ., 8, 1251-1256, 1974.

C̆ervenková, J. and Ván̆a, M.: Trend Assessment of deposition, throughfall and runoff water chemistry at the ICP-IM station Kosetice, Czech Republic, in: Status and Perspectives of Hydrology in Small Basins, edited by: Hermann, A. and Schumann, S., 336, 103-109, IAHS Publications, 2010.

Ulevicius, V., Bycenkiene, S., Remeikis, V., Garbaras, A., Kecorius, S., Andriejauskiene, J., Jasineviciene, D., and Mocnik, G.: Characterization of pollution events in the East Baltic region affected by regional biomass fire emissions, Atmos. Res., 98, 190-200, doi:10.1016/j.atmosres.2010.03.021, 2010.

van Dingenen, R., Raes, F., Putaud, J.-P., Baltensperger, U., Charron, A., Facchini, M.-C., Decesari, S., Fuzzi, S., Gehrig, R., Hansson, H.-C., Harrison, R. M., Huglin, C., Jones, A. M., Laj, P., Maenhaut, G. L. W., Palmgren, F., Querol, X., Rodriguez, S., Schneider, J., ten Brink, H., Tunved, P., Torset, K., Wehner, B., Weingartner, E., Wiedensohler, A., and Wahlin, P.: A European aerosol phenomenology 1: physical characteristics of particulate matter at kerbside, urban, rural and background sites in Europe, Atmos. Environ., 38, 2561-2577, doi:10.1016/j.atmosenv.2004.01.040, 2004. 
Venzac, H., Sellegri, K., Villani, P., Picard, D., and Laj, P.: Seasonal variation of aerosol size distributions in the free troposphere and residual layer at the puy de Dôme station, France, Atmos. Chem. Phys., 9, 1465-1478, doi:10.5194/acp-9-1465-2009, 2009.

Weingartner, E., Nyecki, S., and Baltensberger, U.: Seasonal and diurnal variation of aerosol size distributions $(10<\mathrm{D}<750 \mathrm{~nm})$ at a high-alpine site (Jungfraujoch $3580 \mathrm{~m}$ a.s.1.)., J. Geophys. Res., 104, 26809-26820, 1999.

Wiedensohler, A.: An approximation of the bipolar charge distribution for particles in the submicron range, J. Aerosol Sci., 19, 387-389, 1988.

Wiedensohler, A., Birmili, W., Nowak, A., Sonntag, A., Weinhold, K., Merkel, M., Wehner, B., Tuch, T., Pfeifer, S., Fiebig, M., Fjäraa, A. M., Asmi, E., Sellegri, K., Depuy, R., Venzac, H., Villani, P., Laj, P., Aalto, P., Ogren, J. A., Swietlicki, E., Roldin, P., Williams, P., Quincey, P., Hüglin, C., Fierz-Schmidhauser, R., Gysel, M., Weingartner, E., Riccobono, F., Santos, S., Grüning, C., Faloon, K., Beddows, D., Harrison, R. M., Monahan, C., Jennings, S. G., O’Dowd, C. D., Marinoni, A., Horn, H.-G., Keck, L., Jiang, J., Scheckman, J., McMurry, P. H., Deng, Z., Zhao,
C. S., Moerman, M., Henzing, B., and de Leeuw, G.: Particle mobility size spectrometers: harmonization of technical standards and data structure to facilitate high quality long-term observations of atmospheric particle number size distributions, Atmos. Meas. Tech. Discuss., 3, 5521-5587, doi:10.5194/amtd-3-55212010, 2010.

Wittmaack, K.: In Search of the Most Relevant Parameter for Quantifying Lung Inflammatory Response to Nanoparticle Exposure: Particle Number, Surface Area, or What?, Environ. Health Persp., 115, 2, doi:10.1289/ehp.9254, 2007.

WMO/GAW: WMO/GAW Aerosol measurement procedures guidelines and recommendations, Geneva, $\mathrm{CH}$, no. 153, WMO TD No. 1178, 2003.

Yoon, Y. J., Ceburnis, D., Cavalli, F., Jourdan, O., Putaud, J. P., Facchini, M. C., Decesari, S., Fuzzi, S., Sellegri, K., Jennings, S. G., and O'Dowd, C. D.: Seasonal characteristics of the physicochemical properties of North Atlantic marine atmospheric aerosols, J. Geophys. Res., 112, D04206, doi:10.1029/2005JD007044, 2007. 